\title{
Observations of Coupling between Surface Wind Stress and Sea Surface Temperature in the Eastern Tropical Pacific
}

\author{
Dudley B. Chelton, Steven K. Esbensen, Michael G. Schlax, Nicolai Thum, and \\ MichaEL H. Freilich \\ College of Oceanic and Atmospheric Sciences, Oregon State University, Corvallis, Oregon \\ Frank J. Wentz and Chelle L. Gentemann \\ Remote Sensing Systems, Santa Rosa, California \\ Michael J. McPhaden \\ NOAA/Pacific Marine Environmental Laboratory, Seattle, Washington \\ PAUL S. SCHOPF \\ Institute for Computational Sciences and Informatics, George Mason University, Fairfax, Virginia, and \\ Center for Ocean-Land-Atmosphere Studies, Calverton, Maryland
}

(Manuscript received 27 December 1999, in final form 29 June 2000)

\section{ABSTRACT}

Satellite measurements of surface wind stress from the QuikSCAT scatterometer and sea surface temperature (SST) from the Tropical Rainfall Measuring Mission Microwave Imager are analyzed for the three-month period 21 July-20 October 1999 to investigate ocean-atmosphere coupling in the eastern tropical Pacific. Oceanic tropical instability waves (TIWs) with periods of 20-40 days and wavelengths of 1000-2000 km perturb the SST fronts that bracket both sides of the equatorial cold tongue, which is centered near $1^{\circ} \mathrm{S}$ to the east of $130^{\circ} \mathrm{W}$ These perturbations are characterized by cusp-shaped features that propagate systematically westward on both sides of the equator. The space-time structures of these SST perturbations are reproduced with remarkable detail in the surface wind stress field. The wind stress divergence is shown to be linearly related to the downwind component of the SST gradient with a response on the south side of the cold tongue that is about twice that on the north side. The wind stress curl is linearly related to the crosswind component of the SST gradient with a response that is approximately half that of the wind stress divergence response to the downwind SST gradient. The perturbed SST and wind stress fields propagate synchronously westward with the TIWs. This close coupling between SST and wind stress supports the Wallace et al. hypothesis that surface winds vary in response to SST modification of atmospheric boundary layer stability.

\section{Introduction}

A prominent feature of the eastern tropical Pacific Ocean is a band of cold water near the equator that extends west from South America far into the central equatorial Pacific. The latitude of the coldest water shifts northward from about $2^{\circ} \mathrm{S}$ at about $85^{\circ} \mathrm{W}$ to the equator west of about $130^{\circ} \mathrm{W}$ (Fig. 1a). The intensity and spatial extent of this "cold tongue" vary seasonally (Mitchell and Wallace 1992) and interannually (Deser and Wallace

Corresponding author address: Dudley B. Chelton, College of Oceanic and Atmospheric Sciences, Oregon State University, 104 Ocean Admin. Building, Corvallis, OR 97331-5503.

E-mail: chelton@oce.orst.edu
1990). During normal years, the cold tongue persists from July to November. The southeasterly trade winds blow across this band of cold water and into the intertropical convergence zone (ITCZ) that is located $5^{\circ}-10^{\circ}$ north of the equator. The surface wind stress in this southeasterly cross-equatorial flow decreases by more than a factor of 4 over the cold tongue and then increases by almost the same amount to the north of the cold tongue (Fig. 1b). Wallace et al. (1989) hypothesized that the coincidence of the cold water and light winds is indicative of a coupling between the ocean and the atmosphere in the form of oceanic modification of atmospheric boundary layer stability. The objective of this study is to analyze newly available satellite observations of surface wind stress and sea surface temperature (SST) to investigate this hypothesized ocean-atmosphere interaction. 


\section{July - 20 October 1999}

a) TMI Average Sea Surface Temperature

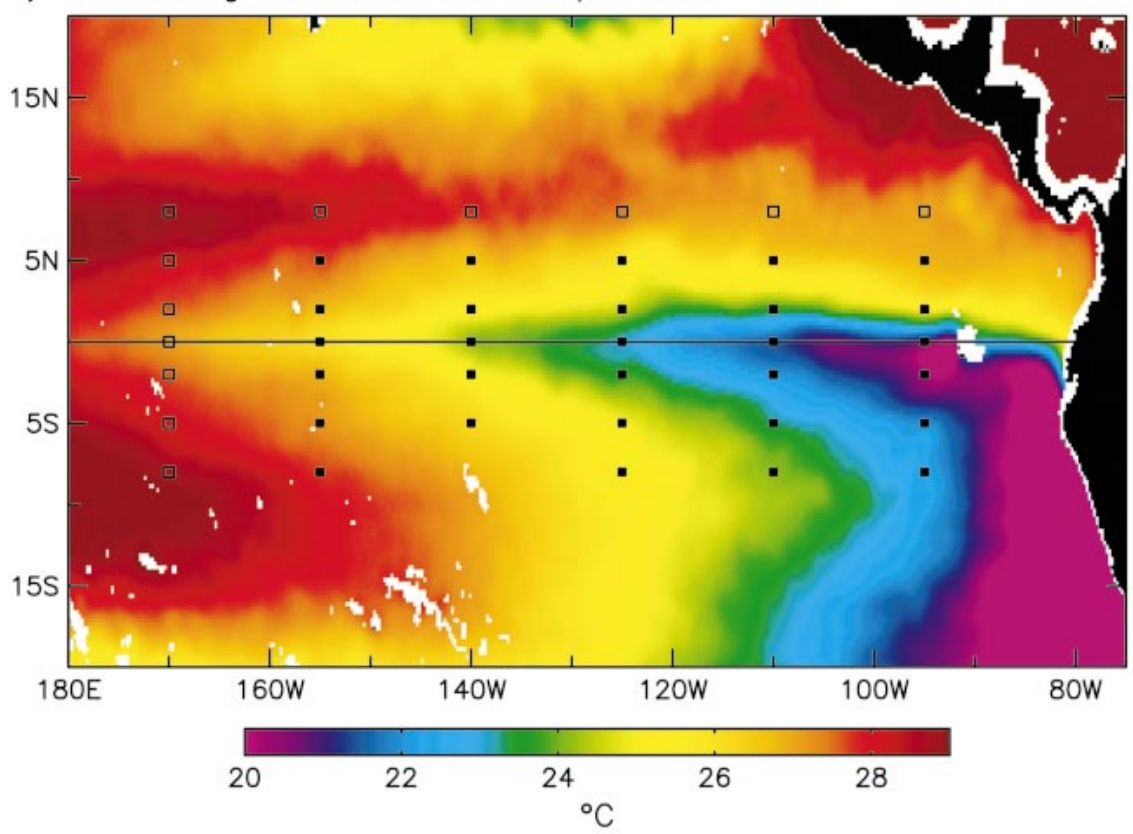

b) QuikSCAT Vector-Average Wind Stress

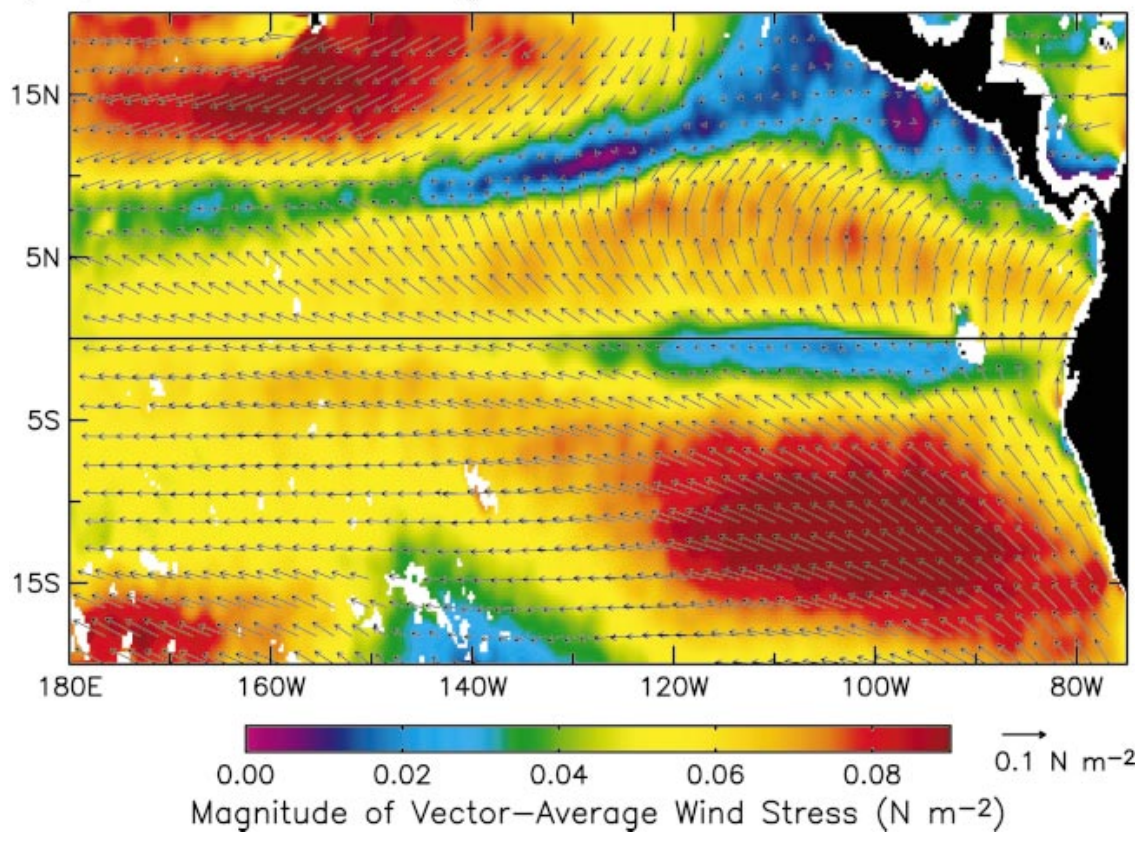

FIG. 1. Three-month averages (21 July-20 October 1999) spatially smoothed to remove variability with wavelengths shorter than $2^{\circ}$ of latitude by $2^{\circ}$ of longitude: (a) TMI measurements of sea surface temperature; and (b) QuikSCAT measurements of surface wind stress. The locations of TAO buoys are shown as squares in (a). The solid squares correspond to the buoys used in section 2 to validate the satellite measurements of SST and winds. The white regions in the maps represent missing data owing to island and continental land contamination in the microwave footprints. The tongue of low wind stress northwest of the Galapagos indicates the presence of a wind shadow that extends almost $200 \mathrm{~km}$ in the lee of the islands. 
The mechanism responsible for the hypothesized coupling between SST and surface wind stress is the change of boundary layer stability that occurs as air from the Southern Hemisphere crosses the cold tongue and blows over the warmer water to the north of the equator. The advection of relatively warm boundary layer air over the cold tongue stabilizes the atmospheric boundary layer and inhibits downward turbulent mixing of northward momentum from aloft. This decoupling of the surface winds from the stronger winds at heights of $100 \mathrm{~m}$ or more above the sea surface (Bond 1992) decelerates the near-surface wind and results in low surface wind stress over the cold water. As the surface winds cross the SST front toward warmer water to the north of the cold tongue, the boundary layer is destabilized and surface sensible heat flux and evaporation increase greatly (Zhang and McPhaden 1995). Convection driven by the enhanced surface heat fluxes increases the downward flux of northward momentum from aloft and accelerates the surface winds toward the north. The downwind acceleration results in a divergence of the surface wind field over the northern SST front. This relationship between the surface wind divergence and the SST field was first hypothesized by Wallace et al. (1989) from an analysis of large-scale climatological average wind and SST fields constructed from historical ship observations.

A unique wavelike feature of the oceanic circulation in the eastern tropical Pacific allows a statistical investigation of the relationship between SST and the surface winds. The intense latitudinal shears between the various components of the equatorial current system (Reverdin et al. 1994) cause the currents to become unstable (Philander 1978; Cox 1980; Luther and Johnson 1990). This generates "tropical instability waves" (TIWs) that propagate westward with periods of 20-40 days, wavelengths of $1000-2000 \mathrm{~km}$, and phase speeds of $\sim 0.5 \mathrm{~m}$ $\mathrm{s}^{-1}$ (Qiao and Weisberg 1995). These unstable waves cause large cusp-shaped meridional perturbations of the SST front along the north side of the cold tongue (Legeckis 1977; Miller et al. 1985; Flament et al. 1996; Kennan and Flament 2000). TIW-induced oceanic eddy heat flux toward the equator has been shown to be comparable to the Ekman heat flux away from the equator and the large-scale net air-sea heat flux over the eastern tropical Pacific (Hansen and Paul 1984; Bryden and Brady 1989; Baturin and Niiler 1997; Wang and McPhaden 1999; Swenson and Hansen 1999). TIWs are thus an important component of the large-scale heat balance of the equatorial cold tongue.

As first noted by Hayes et al. (1989), the space-time variability of the SST signatures of TIWs provides a stringent test of the hypothesized SST-induced atmospheric boundary layer modification. If perturbations of the surface wind stress field are controlled by perturbations of the underlying SST field, then the temporal and spatial variability of the wind stress field should vary quantitatively according to the orientation of the wind direction relative to the TIW-induced perturbations of the SST front. The monthly timescales and $\sim 1500$ $\mathrm{km}$ wavelength of these perturbations of the SST field effectively yield many realizations from which the relationships between winds and SST can be investigated statistically.

Time series of wind and SST measured from buoys along $110^{\circ} \mathrm{W}$ at $2^{\circ} \mathrm{N}$, the equator, and $2^{\circ} \mathrm{S}$ were analyzed by Hayes et al. (1989) to investigate the relationship between TIW-induced perturbations of SST and surface winds. Variations of SST and near-surface winds were found to be consistent with the hypothesized atmospheric boundary layer modification by the underlying SST field. The zonal spacing of moored observations of SST and wind is adequate to investigate the relationship between the meridional components of the gradients of the SST and wind fields but is too coarse to resolve the zonal components of the gradient vectors (see Fig. 4 below). In accord with the expected collocation of wind divergence and SST gradients, Hayes et al. (1989) found a strong correlation between the meridional gradient of SST and the meridional gradient of the northward wind component.

The importance of SST-induced modifications of atmospheric stability has been further investigated from satellite observations of the geographical distribution of low-level cloudiness in relation to the SST signatures of TIWs (Deser et al. 1993). The highest cloud reflectivities were observed over warm SST perturbations, presumably because of increased convective mixing and deepening of the boundary layer in the unstable regime over the warmer water. Although surface wind information was not available, cloud reflectivity was locally high where isotherms were more nearly perpendicular to the climatological average wind direction.

Most recently, TIW-induced modification of the atmospheric boundary layer has been investigated by Xie et al. (1998) from weekly averages of satellite infrared observations of SST and Earth Remote Sensing (ERS-1) scatterometer estimates of the $10-\mathrm{m}$ wind field. The detailed geographical distribution of wind divergence relative to the SST signatures of TIWs was difficult to discern, perhaps because of the severe sampling errors in weekly averaged wind fields constructed from the narrow 500-km swath width of the ERS-1 scatterometer (Schlax et al. 2001). Westward propagation of wind divergence anomalies at apparently the same phase speed as the TIW-induced SST perturbations was nonetheless evident. Xie et al. (1998) interpreted these observations in the context of a coarse-resolution atmospheric model forced by an imposed and spatially fixed SST wave pattern. The model results suggest that TIW-induced perturbations of the low-level winds penetrate well above the atmospheric mixed layer, with variability detectable to at least $800 \mathrm{mb}$ (about $2000 \mathrm{~m}$ above the sea surface). The model also suggests that the TIW-induced variability of the surface wind field may force a deep atmospheric response indicated by measurable precipitation anomalies over the ITCZ. Hashizume et al. 
(2001) have recently presented observational evidence in support of this conclusion.

With the exception of the Hayes et al. (1989) analysis of buoy observations at the equator and $2^{\circ} \mathrm{S}$ along $110^{\circ} \mathrm{W}$, all previous studies of TIW-induced ocean-atmosphere interaction have focused on the region north of the equator. It has recently been shown that TIWinduced perturbations of the SST field also occur south of the equator (Chelton et al. 2000). As the air flows across the perturbed southern SST front, the hypothesized SST modification of atmospheric boundary layer stability predicts that the wind stress will adjust to SST gradients in a manner analogous to the adjustment of the flow across the northern SST front. In regions where the wind blows from warm to cold water, the wind stress should decelerate, resulting in a convergence of lowlevel winds.

The accuracy and spatial resolution limitations of wind fields available heretofore has long been a recognized problem in the Tropics (e.g., Goldenberg and O'Brien 1981; Reynolds et al. 1989). Wind fields constructed from satellite scatterometer observations of surface winds are likely to contribute greatly to an improved understanding of coupled ocean-atmosphere variability in the Tropics. In this study, the hypothesized coupling between the surface wind field and SST in the eastern tropical Pacific is investigated from the first three months of surface wind stress measured by the QuikSCAT scatterometer. SST fields were constructed from near-all-weather satellite observations of SST by the Microwave Imager on board the Tropical Rainfall Measuring Mission (TRMM). By resolving time- and space scales that have previously been unaddressable, these newly available satellite datasets reveal oceanatmosphere interaction with remarkably detailed spacetime structure that supports the coupling between the surface wind stress and SST hypothesized by Wallace et al. (1989) and Hayes et al. (1989).

The satellite measurements of SST and winds are described and validated in section 2 from comparisons with in situ measurements by the Tropical Atmosphere-Ocean (TAO) buoys (McPhaden et al. 1998) in the eastern tropical Pacific. The structure of the relationship between the surface wind stress field and the underlying SST field is presented in section 3, with particular emphasis on the derivative wind stress fields (divergence and curl) and their relationships to the downwind and crosswind components of the SST gradient vector. The synchronous westward propagation of TIW perturbations of the SST and wind stress fields is described in section 4. Implications of the observed coupling between the wind stress and SST are discussed in section 5.

\section{Data description and validation}

The SST data for this study were obtained from the TRMM Microwave Imager (TMI) on board the TRMM satellite (Kummerow et al. 1998). Because the atmo- sphere is nearly transparent to microwave radiation in nonraining conditions, the TMI provides an essentially uninterrupted record of the westward propagation of SST signatures of TIWs (Chelton et al. 2000). Raincontaminated observations are easily identified and eliminated from further analysis based on vertically and horizontally polarized brightness temperatures measured by the radiometer itself (Wentz and Spencer 1998).

The TMI operates at microwave frequencies of 10.7, $19.3,21.3,37.0$, and $85.5 \mathrm{GHz}$. Dual polarization is measured at all frequencies except $21.3 \mathrm{GHz}$, for which only vertical polarization is measured. The primary channel for SST retrievals is $10.7 \mathrm{GHz}$. At this frequency in the absence of rain, the atmospheric contribution to the brightness temperatures is less than $3 \%$. The SST retrieval algorithm uses the 19.3-, 21.3-, and $37.0-\mathrm{GHz}$ channels to remove this small atmospheric signal. The more challenging aspect of the SST retrieval algorithm is the removal of wind speed and wind direction contributions to the $10.7-\mathrm{GHz}$ brightness temperatures. This is achieved by taking advantage of a distinctive polarization dependence of the wind speed and SST signatures in the $10.7-\mathrm{GHz}$ brightness temperatures. The sensitivity of horizontally polarized brightness temperature to wind speed is twice that of vertically polarized brightness temperature. The opposite is true for SST; the sensitivity of horizontally polarized brightness temperature to SST is only half that of vertically polarized brightness temperature. This "orthogonality" allows the simultaneous estimation of wind speed and SST.

There is no distinctive signature of the wind direction effect on $10.7-\mathrm{GHz}$ brightness temperatures that would allow retrievals of wind direction from the TMI passive microwave measurements. At wind speeds below $7 \mathrm{~m}$ $\mathrm{s}^{-1}$, the wind direction signal is very small and does not significantly affect the accuracy of SST retrievals. At higher wind speeds, however, the contribution of the wind direction effect can lead to SST retrieval errors in excess of $1^{\circ} \mathrm{C}$. To reduce these errors, wind direction estimates are obtained from the operational analyses by the National Centers for Environmental Prediction. These wind directions are used to apply a correction to remove the small wind directional effect on the horizontally and vertically polarized brightness temperatures.

A detailed description of the TMI retrieval algorithm is given by Wentz (1998). TMI estimates of SST are obtained from a physically based algorithm that matches the brightness temperatures to a radiative transfer model that is a function of SST, wind speed, columnar water vapor, and columnar cloud liquid water. The algorithm is a direct extension of the algorithm described by Wentz (1997) for retrieval of wind speed, columnar water vapor, and columnar cloud liquid water from the Special Sensor Microwave/Imager (SSM/I). SST cannot be obtained from SSM/I data because of the lack of measurements at $10.7 \mathrm{GHz}$. 

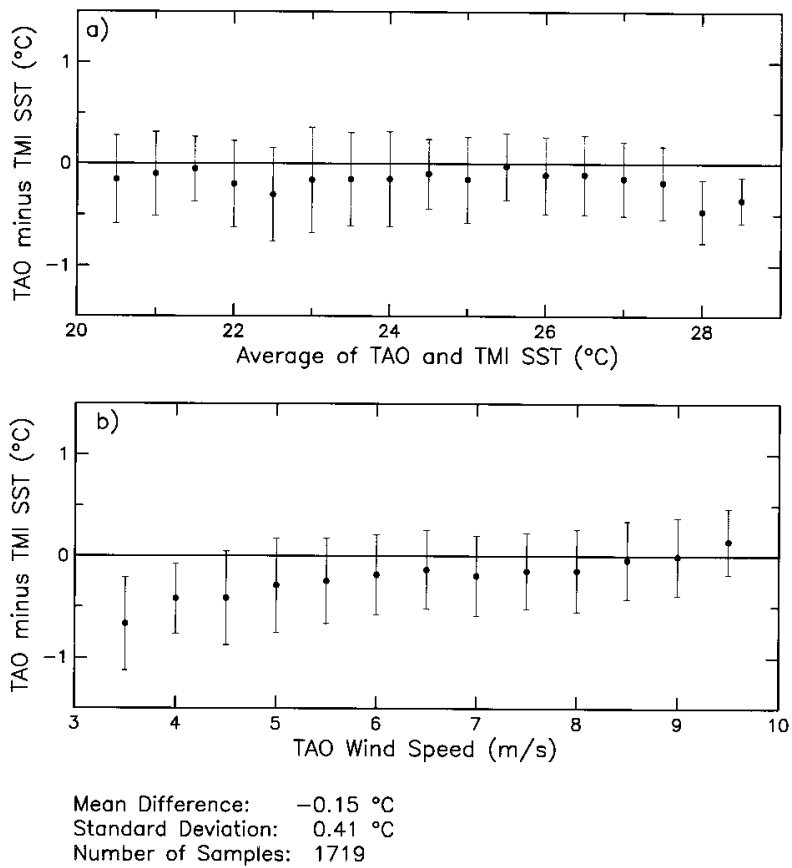

FIG. 2. Binned scatterplot comparison between 3-day averages of TMI measurements of SST and TAO measurements of temperature at a depth of $1 \mathrm{~m}$ at the locations shown by the solid squares in Fig. 1a. The differences between TAO and TMI measurements of temperature were binned as functions of (a) the average of the two temperature measurements; and (b) TAO measurements of wind speed. Solid circles and vertical bars represent the mean and \pm 1 standard deviation of the scatter of points within each bin.

The spatial resolution of TMI measurements of SST is $46 \mathrm{~km}$. Individual measurements have been shown to have an accuracy of $0.5^{\circ} \mathrm{C}$ in rain-free conditions (Wentz 1998). The TMI measurements of SST were validated for the purposes of this study by comparing 3-day composite averages with collocated 3-day averages of in situ measurements of 1-m temperature from the TAO buoys. The buoy locations analyzed here are shown by the solid squares in Fig. 1a. This selection of buoys spans the region of TIW variability that is the focus of this study. The mean and standard deviation of the differences computed from more than 1700 collocated composite averages were $0.15^{\circ} \mathrm{C}$ (TMI higher than TAO) and $0.41^{\circ} \mathrm{C}$, respectively. There was no significant SST dependence of the relative bias or standard deviation (Fig. 2a). There was, however, a small systematic dependence of the relative bias on wind speed; the mean difference increased from about $-0.4^{\circ} \mathrm{C}$ at $4 \mathrm{~m} \mathrm{~s}^{-1}$ to about zero at $9 \mathrm{~m} \mathrm{~s}^{-1}$ (Fig. 2b).

Owing to sensible and evaporative heat fluxes and radiative cooling, the skin temperature in a thin layer at the sea surface is typically a few tenths of a degree Celsius cooler than the bulk temperature in light winds (Saunders 1967). This difference decreases with increasing wind speed and the skin layer is destroyed by whitecapping at wind speeds higher than about $10 \mathrm{~m}$ $\mathrm{s}^{-1}$. Estimates of the thickness of the skin layer in light to moderate winds vary but it is usually considered to be about $1 \mathrm{~mm}$ (Grassl 1976). Since the $e$-folding "optical depth" for microwave radiance at $10.7 \mathrm{GHz}$ is about $1 \mathrm{~mm}$, TMI estimates of SST are less susceptible to skin effects than infrared measurements, for which the optical depth is less than $10 \mu \mathrm{m}$. It therefore seems unlikely that the differences between skin and bulk temperatures would have a significant effect on the calibration of TMI estimates of SST. In any case, the small relative bias between TMI measurements of SST and TAO measurements of 1-m temperature in Fig. 2 is of the opposite sign expected for skin versus bulk temperature differences. The weak systematic dependence of the differences between TAO and TMI temperature measurements on wind speed in Fig. $2 b$ may therefore be an indication that the wind speed effects on the microwave brightness temperatures have not been completely removed in the TMI SST retrieval algorithm.

For present purposes, the conclusions of this study are not significantly altered by the possible small systematic error in TMI estimates of SST. We conclude that the SST fields constructed from 3-day averages of TMI data are sufficiently accurate to investigate the coupling between SST and the overlying wind field on the timeand space scales of interest in this study.

The surface vector winds analyzed here were obtained from the SeaWinds scatterometer (Freilich et al. 1994) launched on 19 June 1999 on board the QuikSCAT satellite. The geophysical data record began on 15 July 1999. The 3-month data record analyzed here extends from 21 July to 20 October 1999. As described in detail by Naderi et al. (1991), scatterometers infer wind stress magnitude and direction from measurements of microwave radar backscatter received from a given location on the sea surface at multiple antenna look angles. The wind retrievals are calibrated to the so-called neutralstability wind at a height of $10 \mathrm{~m}$ above the sea surface, that is, the wind that would exist if the atmospheric boundary layer were neutrally stable. The vector wind stress $\boldsymbol{\tau}$ and $10-\mathrm{m}$ neutral stability vector wind $\mathbf{v}_{10}^{N}$ are simply related by $\boldsymbol{\tau}=\rho C_{d}^{N} \mathbf{v}_{10}^{N}\left|\mathbf{v}_{10}^{N}\right|$, where $\rho \approx 1.2 \mathrm{~kg}$ $\mathrm{m}^{-3}$ is the air density and $C_{d}^{N}$ is the neutral stability drag coefficient (Large and Pond 1981).

The QuikSCAT instrument measures vector winds with $25-\mathrm{km}$ resolution over a single $1600-\mathrm{km}$ swath centered on the satellite ground track. The superiority of QuikSCAT coverage compared with previous scatterometers is discussed in detail by Schlax et al. (2001). The 1600-km QuikSCAT swath width is 33\% greater than its predecessor, the dual-swath National Aeronautics and Space Administration scatterometer (NSCAT), and more than $300 \%$ greater than the narrow $500-\mathrm{km}$ single-swath scatterometers on board the ERS-1 and ERS-2 satellites launched by the European Space Agency. These sampling differences have a major impact on the accuracies of wind fields constructed from the various scatterometer datasets (Schlax et al. 2001). Sampling errors are especially a concern in the derivative 
wind fields (divergence and curl) that are of interest here in sections 3 and 4 .

Rain-contaminated QuikSCAT observations were flagged and eliminated from subsequent analysis by comparison with rain estimates from the three SSM/I satellites $(F 11, F 13$, and $F 14)$ that are in operation simultaneous with QuikSCAT. A QuikSCAT observation was flagged when the nearest SSM/I measurement within $50 \mathrm{~km}$ and $1 \mathrm{~h}$ yielded a nonzero rain-rate estimate based on the algorithm described by Wentz and Spencer (1998). The closest collocations of SSM/I and QuikSCAT measurements were usually with the $F 13$ satellite.

The prelaunch algorithm used to derive the QuikSCAT vector winds analyzed in this study was assessed by comparing 3-day composite scalar averages of QuikSCAT wind speeds with collocated 3-day scalaraverage wind speeds measured from the TAO buoys. Daily average TAO winds were converted to $10-\mathrm{m}$ neutral stability wind speeds based on TAO measurements of air-sea temperature difference and surface humidity using the algorithm described by Fairall et al. (1996). The daily average TAO wind speeds were then scalar averaged to form 3-day averages for comparison with scalar-average QuikSCAT wind speeds. The mean and standard deviation of the differences computed from more than 1700 collocated composite averages were $0.74 \mathrm{~m} \mathrm{~s}^{-1}$ (TAO higher than QuikSCAT) and $0.71 \mathrm{~m}$ $\mathrm{S}^{-1}$, respectively. There were no significant dependencies of the relative bias or standard deviation on SST (Fig. 3a) or wind speed (Fig. 3b).

The TAO wind speed measurement accuracy has been estimated as $0.3 \mathrm{~m} \mathrm{~s}^{-1}$ (Dickinson et al. 2001). Most of this measurement uncertainty is due to calibration drifts. The error is therefore not significantly reduced in the 3-day averages considered here. A root sum of squares partitioning of the $0.71 \mathrm{~m} \mathrm{~s}^{-1}$ standard deviation of the difference between TAO and QuikSCAT wind speeds thus suggests an uncertainty of $0.64 \mathrm{~m} \mathrm{~s}^{-1}$ for the random component of QuikSCAT wind speed measurement errors in the 3-day averages considered here.

The systematic $0.74 \mathrm{~m} \mathrm{~s}^{-1}$ mean difference in Fig. 3 may be an indication that the wind speeds from the QuikSCAT prelaunch algorithm are biased slightly low. A comprehensive calibration and validation study is underway by the QuikSCAT Science Working Team. For the purposes of this study, a bias of the QuikSCAT wind speeds has no effect on the derivative wind stress fields (divergence and curl) that are of primary interest in sections 3 and 4 . The prelaunch algorithm is therefore adequate to address the coupling between the surface wind stress field and the underlying SST field; the conclusions of this study are not altered if the QuikSCAT wind retrievals are adjusted to remove the possible 0.74 $\mathrm{m} \mathrm{s}^{-1}$ bias.

The daily average wind observations available from the TAO buoys for the time period analyzed here are not adequate to assess the directional accuracy of the QuikSCAT vector winds. Freilich et al. (2000, unpub-
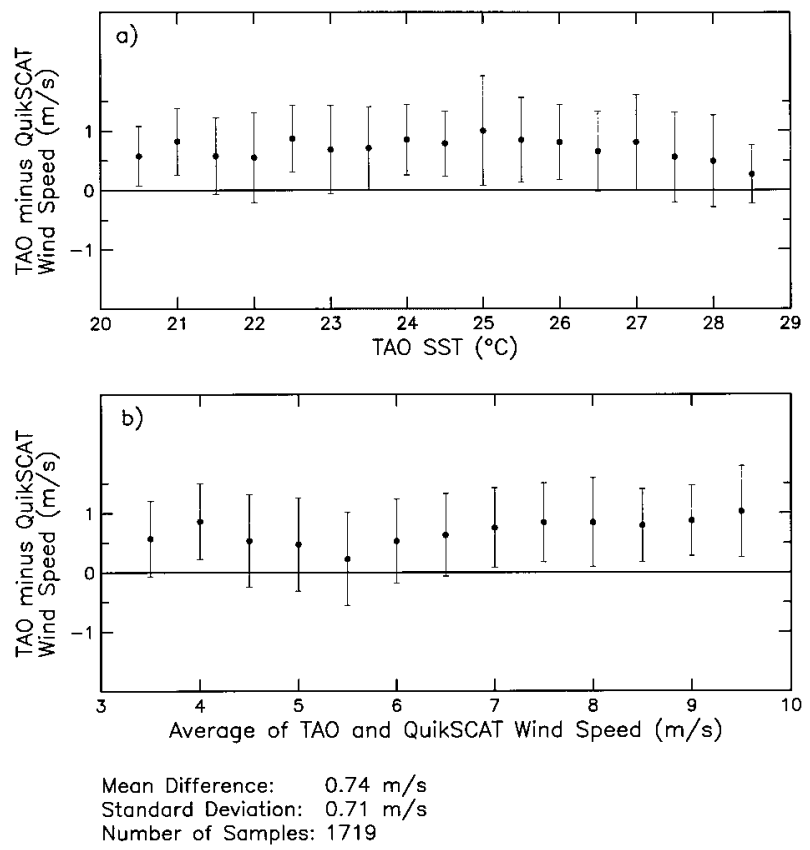

FIG. 3. Binned scatterplot comparisons between 3-day averages of QuikSCAT and TAO measurements of $10-\mathrm{m}$ neutral-stability winds at the locations shown by the solid squares in Fig. 1a. The differences between TAO and QuikSCAT wind speeds were binned as functions of (a) TAO measurements of temperature at a depth of $1 \mathrm{~m}$; and (b) the average of the two wind speed measurements. Solid circles and vertical bars represent the mean and \pm 1 standard deviation of the scatter of points within each bin.

lished manuscript, hereafter FVD) have compared the QuikSCAT wind directions with over 12000 buoy observations of winds collected by the National Data Buoy Center and concluded that the standard deviation of the directional difference is $27^{\circ}$. The directional accuracy is better characterized in terms of the random component error, which FVD find to be about $0.7 \mathrm{~m} \mathrm{~s}^{-1}$ for each orthogonal component with no significant dependence on the wind speed. The directional uncertainty of the QuikSCAT winds thus decreases rapidly with increasing wind speed (see also Freilich and Dunbar 1999).

\section{The coupling between SST and wind stress}

A recent analysis of TMI measurements of the westward-propagating SST signatures of TIWs (Chelton et al. 2000) revealed that Pacific TIWs were very energetic, both north and south of the equator, during the 3-month period considered here. This period coincides with a La Niña year, during which TIWs are generally found to be most energetic. This is in contrast to the NSCAT observational period, September 1996-June 1997, during which TIW amplitudes were small (Chelton et al. 2001, manuscript submitted to J. Phys. Ocean$o g r$.). Contemporaneous QuikSCAT and TMI data thus offer the first opportunity for high-resolution and dense sampling of TIW-induced ocean-atmosphere interaction in the tropical Pacific. 


\section{2-4 September 1999}

a) TMI Sea Surface Temperature

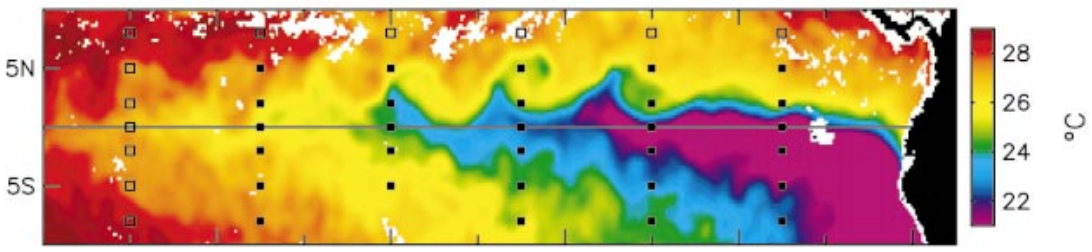

b) QuikSCAT Wind Stress Magnitude with SST Overlaid

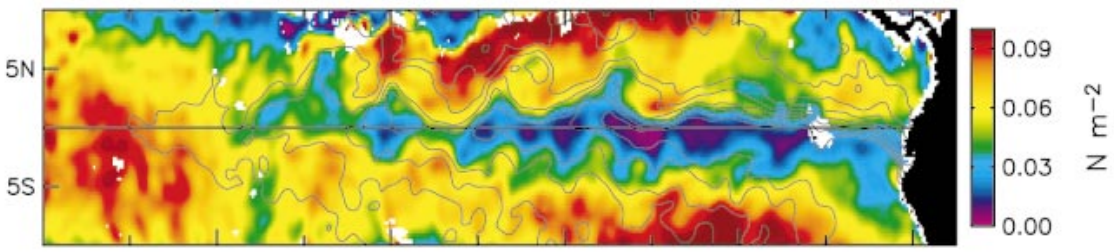

c) QuikSCAT Wind Stress with SST Overlaid $\quad \overrightarrow{0.1} \mathrm{~N} \mathrm{~m}^{-2}$

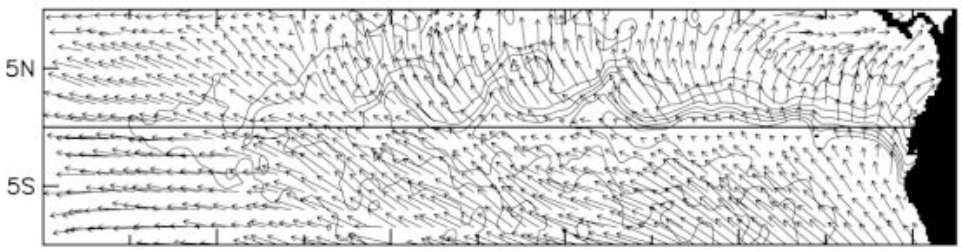

d) QuikSCAT Wind Stress Divergence with SST Overlaid

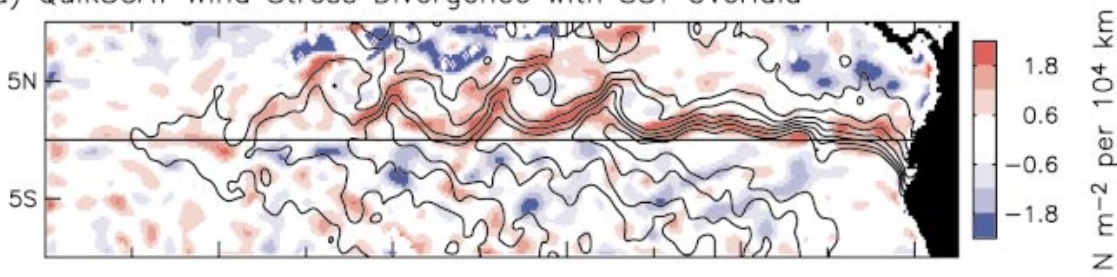

e) QuikSCAT Wind Stress Curl with SST Overlaid

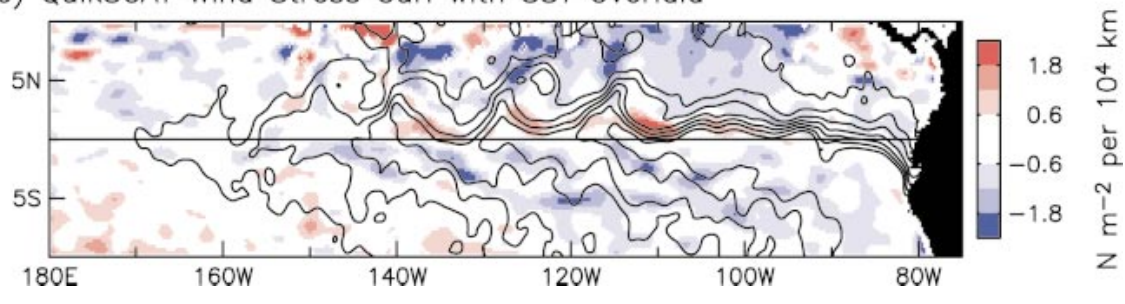

FIG. 4. Three-day average maps over the period 2-4 September 1999: (a) sea surface temperature with TAO mooring locations shown as squares; (b) wind stress magnitude; (c) wind stress; (d) wind stress divergence; and (e) wind stress curl. The contours overlaid in (b)-(e) correspond to isotherms at intervals of $1^{\circ} \mathrm{C}$ between $21^{\circ}$ and $27^{\circ} \mathrm{C}$. The SST and wind stress fields were smoothed to remove variability with wavelengths shorter than $2^{\circ}$ of latitude by $2^{\circ}$ of longitude. To suppress the amplification of sampling errors, the derivative fields (divergence and curl) were further smoothed zonally to remove variability with wavelengths shorter than $4^{\circ}$ of longitude.

A 3-day average map of SST is shown in Fig. 4a for the period 2-4 September 1999, which is a representative time period during the 3-month data record analyzed in this study. ${ }^{1}$ The cusp-shaped features of the

\footnotetext{
${ }^{1}$ Animations of the SST and wind fields can be downloaded from anonymous ftp by contacting the corresponding author at chelton@ oce.orst.edu.
}

SST front along the north side of the equatorial cold tongue are characteristic of TIWs (Legeckis 1977). Note the clockwise rotation of the northern tips of the cold cusps along the northern SST front at about $160^{\circ}, 148^{\circ}$, $139^{\circ}$, and $128^{\circ} \mathrm{W}$. Clockwise rotation is especially clear at $128^{\circ} \mathrm{W}$. These features are indicative of anticyclonic particle velocities in the warm regions between successive cusps (Hansen and Paul 1984; Flament et al. 1996; Kennan and Flament 2000; Weidman et al. 1999). Each 
of the cold cusps is reproduced with remarkable fidelity in the corresponding 3-day average maps of the wind stress shown in Figs. 4b,c. A similar coincidence of TIW-related perturbations of SST and wind stress magnitude is evident along the weaker cusp-shaped southern SST front. The wind stress is higher over warm water and lower over cold water. As summarized in the introduction, the close relationship between SST and wind stress magnitude is at least qualitatively consistent with the SST-induced modification of atmospheric boundary layer stability hypothesized by Wallace et al. (1989). This relation is quantified below.

The effects of SST-induced changes of atmospheric stability on the overlying wind stress depend on both the SST gradient and the wind direction relative to the SST gradient vector. There is therefore no general linear relation between the gradient of the wind stress magnitude and the SST gradient. The wind stress response to geographical variations of the underlying SST field can be better characterized in terms of the wind stress divergence, $\boldsymbol{\nabla} \cdot \boldsymbol{\tau}$, shown in Fig. $4 \mathrm{~d}$. In the Northern Hemisphere, a band of high divergence follows the cusp patterns along the northern SST front where the wind stress increases as the air flows across isotherms toward warmer water. The largest wind stress divergences are located directly over the strongest SST gradients. It is visually apparent that the divergence is locally larger where the wind stress is aligned perpendicular to isotherms (i.e., parallel to the SST gradient vector).

The importance of the alignment between the wind stress and the SST gradient is also apparent from the relationship between the wind stress divergence and SST south of the equator. The SST gradients are weaker and spatially irregular and the isotherms tend to be more nearly aligned with the wind stress vectors, resulting in relatively small SST-induced downwind modification of the wind stress. Convergence of the wind stress is nonetheless apparent in patches where the wind stress decreases as the air flows across perturbed isotherms toward cooler water.

The hypothesized SST modification of the wind stress field can be independently investigated from the relationship between the crosswind SST gradient and the vertical component of the wind stress curl, $\boldsymbol{\nabla} \times \boldsymbol{\tau} \cdot \hat{\mathbf{k}}$, where $\hat{\mathbf{k}}$ is a unit vector in the vertical direction. Along the cuspy northern SST front, the wind stress curl is positive where the winds blow parallel to isotherms (i.e., perpendicular to the SST gradient vector; see Fig. 4e). This pattern in the wind stress curl field develops because the winds are stronger over the warmer water to the right of the wind direction, resulting in a lateral gradient of the wind stress that corresponds to a positive wind stress curl. As the winds over the region of interest blow toward the northwest during the 3-month period considered here (see Figs. 1b and 4c), the largest wind stress curl occurs on the southwestern boundaries of the warm anomalies between successive cold SST cusps (see Fig. 4e).
In the Southern Hemisphere, large negative wind stress curl occurs in patches where the wind blows parallel to perturbed isotherms in regions where water is warmer to the left of the wind direction. The latitudinal extent of this band of negative wind stress curl is much wider and the magnitudes are somewhat weaker than in the northern band of positive wind stress curl because the southern SST front is much broader than the northern SST front (see Figs. 1a and 4a).

The band of persistent negative wind stress curl north of about $3^{\circ} \mathrm{N}$ in Fig. $4 \mathrm{e}$ is noteworthy. This feature is a manifestation of large-scale eastward curving of the cross-equatorial winds (see Fig. 1b). Lindzen and Nigam (1987), Mitchell and Wallace (1992), and others have noted that the contrast between the cool atmospheric boundary layer air over the equatorial cold tongue and the warmer air to the north enhances the northward sea level pressure gradient in this region. The anticyclonic turning of the cross-equatorial flow north of $3^{\circ} \mathrm{N}$ where the Coriolis acceleration becomes important may occur because of geostrophic adjustment of the vertically integrated boundary layer flow to the SST-enhanced poleward pressure gradient (e.g., Young 1987; Tomas et al. 1999). This adjustment process is physically distinct from the SST-induced boundary layer modification of interest in this study. The statistical analyses of TIWinduced perturbations of the wind stress fields that follow are therefore restricted to the latitude range from $3^{\circ} \mathrm{N}$ to $5^{\circ} \mathrm{S}$.

If the relations between the derivative wind stress fields and the underlying SST field described qualitatively above from the case study shown in Fig. 4 are quantitatively correct, then the wind stress divergence will vary in proportion to the downwind SST gradient. This component of $\nabla T$ is given by the vector dot product $\boldsymbol{\nabla} T \cdot \hat{\boldsymbol{\tau}}=|\boldsymbol{\nabla} T| \cos \theta$, where $T$ is SST, $\hat{\boldsymbol{\tau}}$ is a unit vector in the direction of the wind stress, and $\theta$ is the counterclockwise angle from the vector $\nabla T$ to $\hat{\boldsymbol{\tau}}$. Similarly, the wind stress curl will vary in proportion to the crosswind component of the SST gradient that can be characterized by the vector cross product $\nabla T \times \hat{\boldsymbol{\tau}} \cdot \hat{\mathbf{k}}=|\nabla T|$ $\sin \theta$.

Quantifying the relation between the derivative wind stress fields and the angle $\theta$ is complicated by the highly nonuniform (bimodal) distribution of $\theta$ (see thick solid line in Fig. 5a). As shown by the dashed line in Fig. $5 \mathrm{a}$, the peak in the histogram centered near $\theta=-100^{\circ}$ is composed almost entirely of observations within the region south of the cold tongue $\left(1^{\circ}-5^{\circ} \mathrm{S}\right)$ where the winds blow approximately parallel to isotherms (i.e., $\nabla T$ and $\hat{\tau}$ are approximately orthogonal). Similarly, it is apparent from the thin solid line in Fig. 5a that the peak in the histogram centered near $\theta=30^{\circ}$ is composed almost entirely of observations within the region north of the cold tongue $\left(3^{\circ} \mathrm{N}-1^{\circ} \mathrm{S}\right)$ where the winds blow obliquely across isotherms.

The 3-month statistics of the dependencies of the magnitudes of $\boldsymbol{\nabla} T$ and $\boldsymbol{\nabla}|\boldsymbol{\tau}|$ on $\theta$ are summarized in 

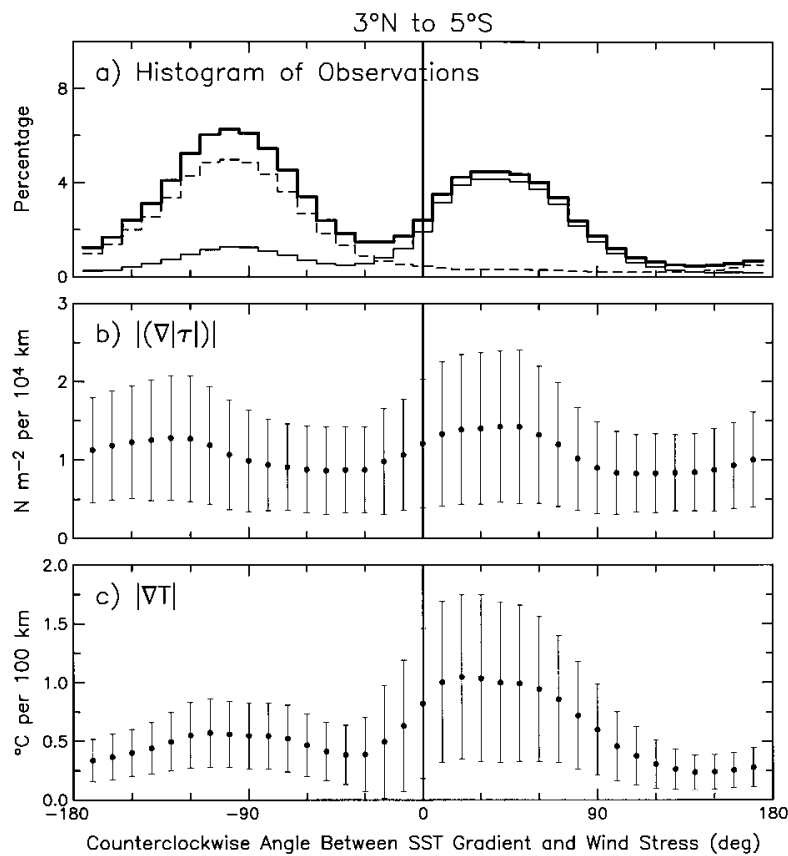

FIG. 5. Binned scatterplots of the angular dependencies of (a) the number of observations for the longitude range $150^{\circ}-100^{\circ} \mathrm{W}$ and the latitude range $3^{\circ} \mathrm{N}-5^{\circ} \mathrm{S}, 3^{\circ} \mathrm{N}-1^{\circ} \mathrm{S}$ on the north side of the cold tongue (thin solid line) and $1^{\circ}-5^{\circ} \mathrm{S}$ on the south side of the cold tongue (dashed line); (b) the magnitude of $\boldsymbol{\nabla}|\boldsymbol{\tau}|$; (c) the magnitude of $\boldsymbol{\nabla} T$. The abscissa is the counterclockwise angle $\theta$ from the SST gradient vector $\boldsymbol{\nabla} T$ to the wind stress vector $\boldsymbol{\tau}$. The solid circles and vertical bars in (b) and (c) represent the mean and \pm 1 standard deviation of the scatter of points within each bin over the latitude range $3^{\circ} \mathrm{N}-5^{\circ} \mathrm{S}$ and the longitude range $150^{\circ}-100^{\circ} \mathrm{W}$.

Figs. 5b,c. The mean values of $|\nabla T|$ were largest near the peaks in the histogram of $\theta$. Note also that $|\nabla T|$ was about a factor of 2 larger on the north side of the cold tongue (positive $\theta$ ) than on the south side of the cold tongue (negative $\theta$ centered near $100^{\circ}$ ). In contrast, the peaks in the histogram of $|(\boldsymbol{\nabla}|\boldsymbol{\tau}|)|$ had similar amplitudes on opposite sides of the cold tongue. These differences in the northern versus southern magnitudes of $\nabla T$ and $\boldsymbol{\nabla}|\boldsymbol{\tau}|$ are visually apparent from the mean SST and wind stress fields in Fig. 1. This is discussed further below.

The biases in the distributions of $\theta$ and $|\nabla T|$ make it difficult to isolate the predicted sinusoidal dependencies of $\boldsymbol{\nabla} \cdot \boldsymbol{\tau}$ and $\boldsymbol{\nabla} \times \boldsymbol{\tau} \cdot \hat{\mathbf{k}}$ on $\theta$ since not all angles $\theta$ are adequately sampled. These biases are greatly reduced by isolating the TIW-induced perturbations that are of interest here by zonally high-pass filtering the downwind and crosswind SST gradient fields and the wind stress fields to remove variability with zonal wavelengths longer than $20^{\circ}$ of longitude (about $2200 \mathrm{~km}$ ). This filter cutoff is long enough to retain the 10002000-km wavelengths of TIWs yet short enough to remove the large-scale background wind variability that is unrelated to TIW-induced perturbations of the SST field. The perturbation downwind and crosswind SST gradients will be denoted by $(\boldsymbol{\nabla} T \cdot \hat{\boldsymbol{\tau}})^{\prime}$ and $(\boldsymbol{\nabla} T \times$
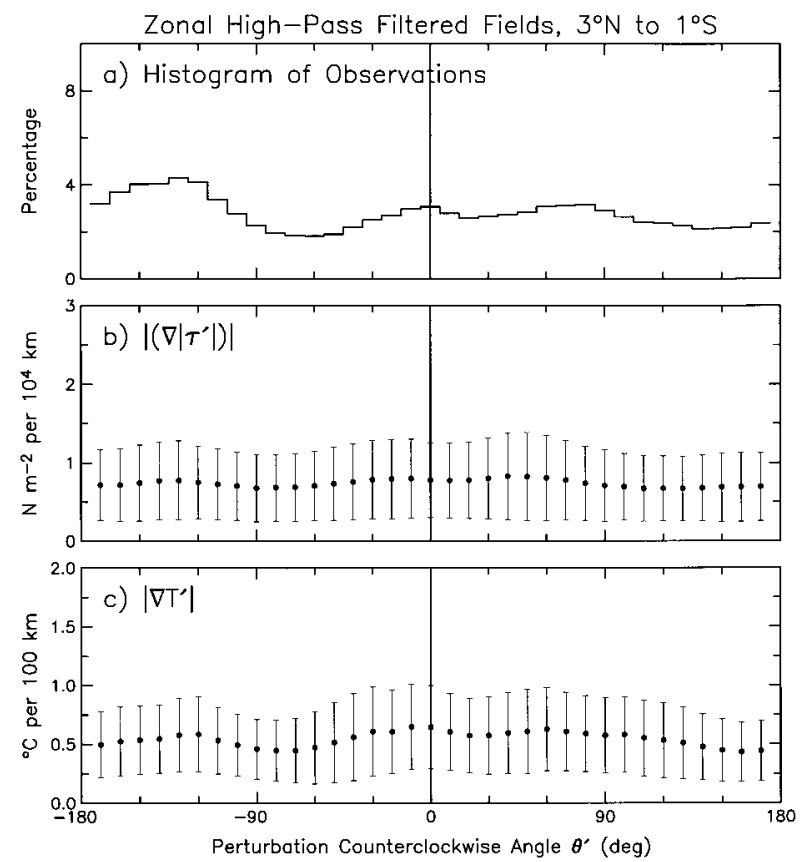

FIG. 6. The same as Fig. 5, except for the perturbation SST and wind stress fields, $T^{\prime}$ and $\tau^{\prime}$, over the longitude range $150^{\circ}-100^{\circ} \mathrm{W}$ and the latitude range $3^{\circ} \mathrm{N}-1^{\circ} \mathrm{S}$ on the north side of the cold tongue. The abscissa is the perturbation counterclockwise angle $\theta^{\prime}$ defined in the text.

$\hat{\tau})^{\prime} \cdot \hat{\mathbf{k}}$, respectively. The perturbation wind stress will be denoted by $\tau^{\prime}$. If the hypothesized dependence between the derivative wind stress and SST gradient fields is valid on the time- and space scales of the TIW-induced perturbations, then we would expect $\boldsymbol{\nabla} \cdot \boldsymbol{\tau}^{\prime}$ to be linearly related to $(\boldsymbol{\nabla} T \cdot \hat{\boldsymbol{\tau}})^{\prime}$. Likewise, $\boldsymbol{\nabla} \times \boldsymbol{\tau}^{\prime}$ should be linearly related to $(\nabla T \times \hat{\boldsymbol{\tau}})^{\prime} \cdot \hat{\mathbf{k}}$. These linear relations imply that the perturbation wind stress divergence and curl should depend, respectively, on the cosine and sine of the perturbation angle defined by

$$
\theta^{\prime}=\tan ^{-1}\left[\frac{(\boldsymbol{\nabla} T \times \hat{\boldsymbol{\tau}})^{\prime} \cdot \hat{\mathbf{k}}}{(\boldsymbol{\nabla} T \cdot \hat{\boldsymbol{\tau}})^{\prime}}\right] .
$$

In anticipation of the different sensitivities of the derivative wind stress fields to SST gradients that are deduced below, the observations were also segregated into $4^{\circ}$ latitudinal bands straddling the cold tongue centered near $1^{\circ} \mathrm{S}$. As shown in Figs. 6 and 7, the distributions of $\theta^{\prime},\left|\left(\nabla\left|\boldsymbol{\tau}^{\prime}\right|\right)\right|$ and $\left|\nabla T^{\prime}\right|$ within each latitude band are much more nearly uniform than in the full SST and wind stress fields shown in Fig. 5.

The 3-month statistics of the dependencies of the zonally high-pass filtered wind stress divergence on the angle $\theta^{\prime}$ for the regions north and south of the cold tongue are summarized in Fig. 8. In both latitude bands, there is remarkably good agreement between the binned mean values of $\boldsymbol{\nabla} \cdot \boldsymbol{\tau}^{\prime}$ and the expected cosine dependence on $\theta^{\prime}$. Similarly, the dependencies of the zonally high-pass filtered binned mean values of wind stress curl 
Zonal High-Pass Filtered Fields, $1^{\circ} \mathrm{S}$ to $5^{\circ} \mathrm{S}$
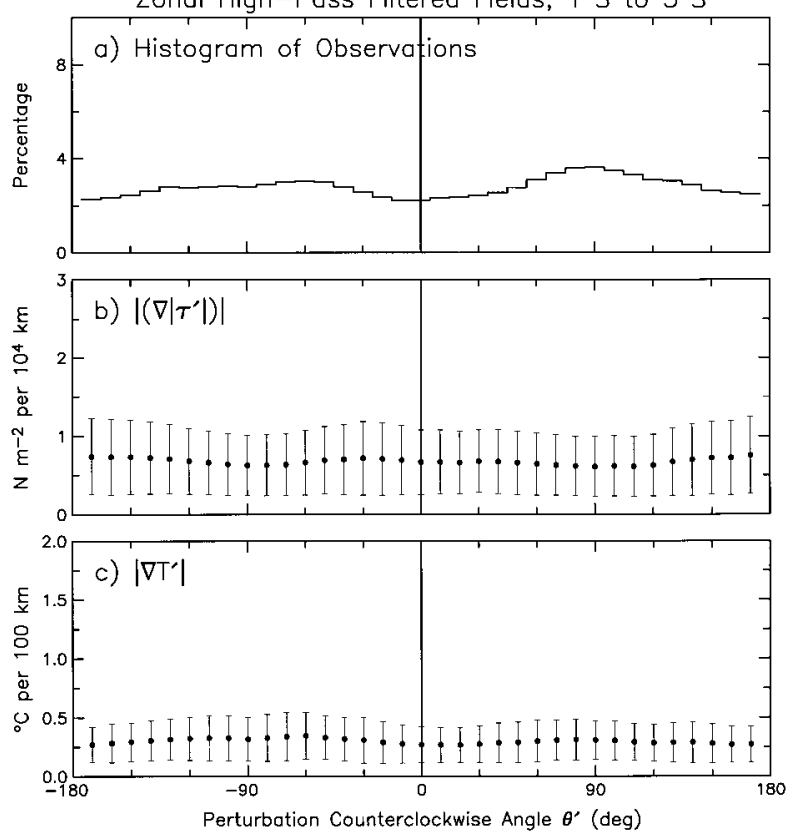

FIG. 7. The same as Fig. 6, except for the perturbation SST and wind stress fields, $T^{\prime}$ and $\tau^{\prime}$, over the longitude range $150^{\circ}-100^{\circ} \mathrm{W}$ and the latitude range $1^{\circ}-5^{\circ} \mathrm{S}$ on the south side of the cold tongue.

on $\theta^{\prime}$ agree very well with the expected sine dependence on $\theta^{\prime}$ (Fig. 9). At least on the spatial and temporal scales of TIWs, these results confirm the hypothesized dependencies of the derivative wind stress fields on the orientation of the wind stress relative to the SST gradient; the binned mean wind stress divergence or convergence is largest when the winds blow parallel to the SST gradient (across isotherms) and zero when the winds blow perpendicular to the SST gradient. Conversely, the binned mean wind stress curl is largest when the winds blow perpendicular to the SST gradient (along isotherms) and zero when the winds blow parallel to the SST gradient.

The statistical relationships between the perturbation derivative wind stress fields and the underlying perturbation SST gradient field over the 3-month period considered in this study are quantified for the regions north and south of the cold tongue in Figs. 10 and 11, respectively. As expected from the cosine dependencies in Fig. 8, the binned mean values of the perturbation wind stress divergence, $\boldsymbol{\nabla} \cdot \boldsymbol{\tau}^{\prime}$, vary linearly with the downwind perturbation SST gradient, $(\boldsymbol{\nabla} T \cdot \hat{\boldsymbol{\tau}})^{\prime}$, both north and south of the cold tongue (Figs. 10a and 11a). The different slopes of linear fits to the mean values in each bin indicate an asymmetric sensitivity of wind stress divergence to SST gradients on opposite sides of the cold tongue; for a given magnitude of temperature change, the change of $\boldsymbol{\nabla} \cdot \boldsymbol{\tau}^{\prime}$ for winds blowing across the southern SST front is about double the corresponding change of $\boldsymbol{\nabla} \cdot \boldsymbol{\tau}^{\prime}$ for winds blowing across the northern SST front.

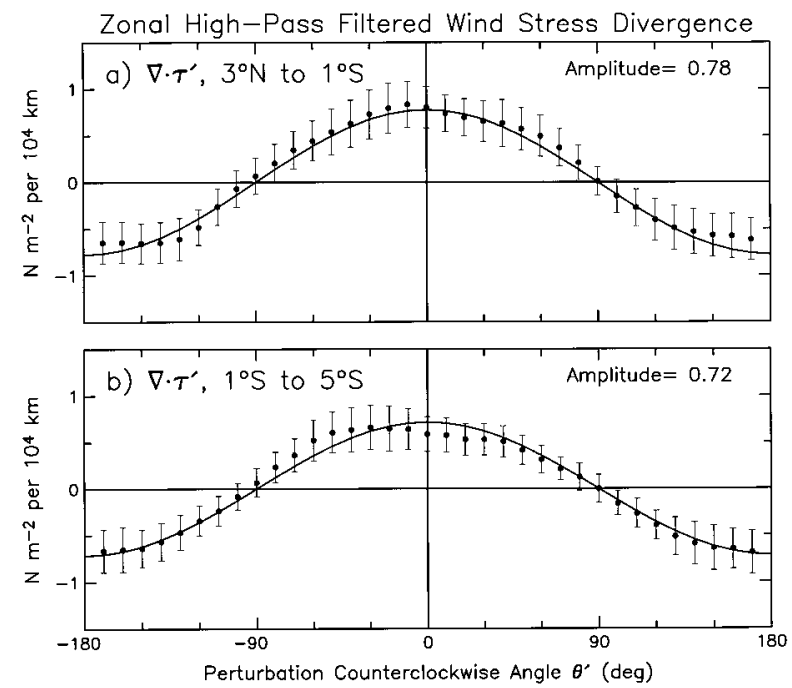

FIG. 8. Binned scatterplots of the angular dependencies of zonally high-pass filtered wind stress divergence, $\boldsymbol{\nabla} \cdot \boldsymbol{\tau}^{\prime}$, over the longitude range $150^{\circ}-100^{\circ} \mathrm{W}$ for (a) the latitude range $3^{\circ} \mathrm{N}-1^{\circ} \mathrm{S}$ on the north side of the cold tongue; and (b) the latitude range $1^{\circ}-5^{\circ} \mathrm{S}$ on the south side of the cold tongue. The solid circles represent the overall mean values within each bin over the 3-month data record. The associated vertical bars represent the \pm 1 standard deviation of the mean values within each bin computed individually for each 3-day period over the 3-month data record. These standard deviations provide a measure of the uncertainty of the estimate of the overall mean in each bin. The smooth curves represent least squares fits of the binned overall means to a cosine.

The asymmetry of the response of the wind stress divergence on opposite sides of the cold tongue is also qualitatively apparent from Figs. 1a,b, and Figs. 5b,c. As noted previously, the mean SST gradient north of the cold tongue is about twice the mean SST gradient

Zonal High-Pass Filtered Wind Stress Curl
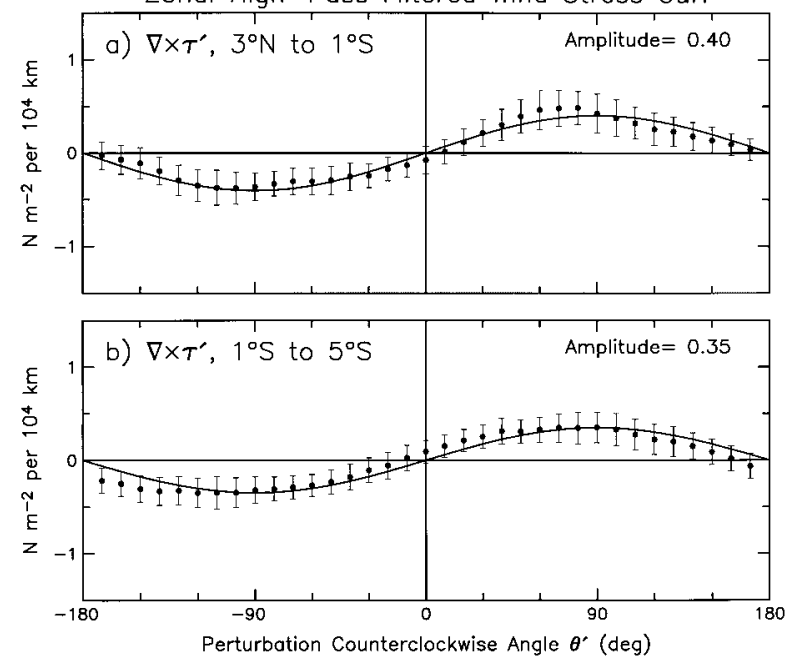

FIG. 9. The same as Fig. 8, except the angular dependencies of zonally high-pass filtered wind stress curl, $\boldsymbol{\nabla} \times \boldsymbol{\tau}^{\prime} \cdot \hat{\mathbf{k}}$. The smooth curves represent least squares fits of the binned overall means to a sine. 

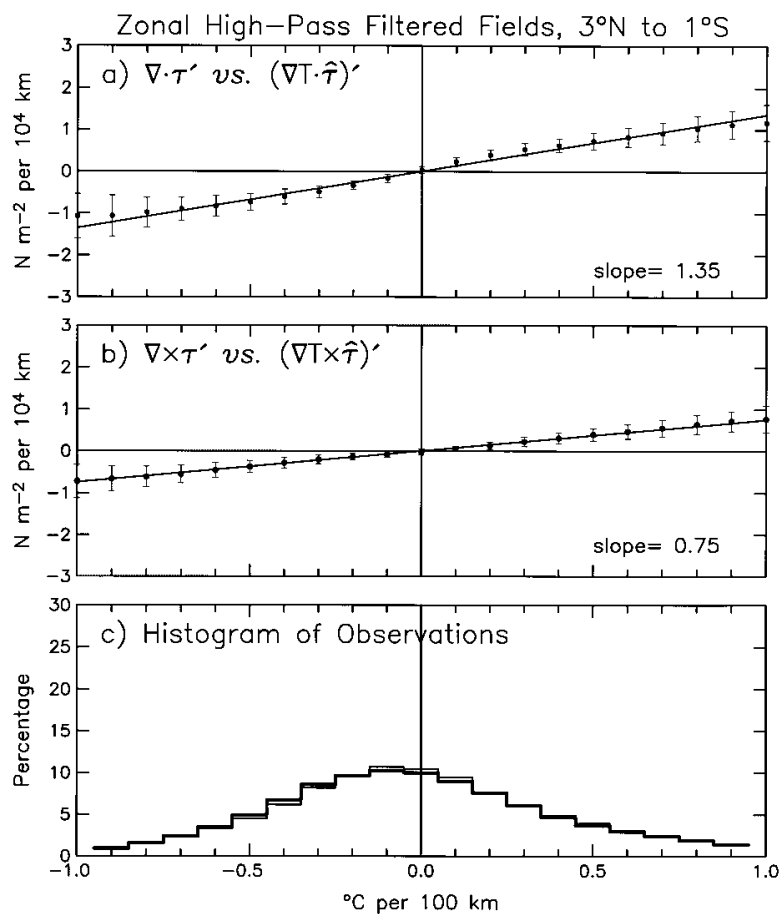

FIG. 10. Binned scatterplots of the relationships between the zonally high-pass filtered SST and wind stress fields in the longitude range $150^{\circ}-100^{\circ} \mathrm{W}$ and the latitude range $3^{\circ} \mathrm{N}-1^{\circ} \mathrm{S}$ on the north side of the cold tongue: (a) the perturbation wind stress divergence, $\boldsymbol{\nabla} \cdot \boldsymbol{\tau}^{\prime}$, plotted as a function of the perturbation downwind SST gradient, $(\boldsymbol{\nabla} T \cdot \hat{\boldsymbol{\tau}})^{\prime} ;\left(\right.$ b) the perturbation wind stress curl, $\boldsymbol{\nabla} \times \boldsymbol{\tau}^{\prime} \cdot \hat{\mathbf{k}}$, plotted as a function of the perturbation crosswind SST gradient, $(\nabla T \times$ $\hat{\boldsymbol{\tau}})^{\prime} \cdot \hat{\mathbf{k}}$; and (c) histograms of the number of observations within each bin for (a) (thick line) and (b) (thin line). The solid circles in (a) and (b) represent the overall mean values within each bin over the 3 -month data record. The associated vertical bars represent the \pm 1 standard deviation of the mean values within each bin computed individually for each 3-day period over the 3-month data record. These standard deviations provide a measure of the uncertainty of the estimate of the overall mean in each bin. The smooth lines through the binned means represent least squares fits of the binned overall means to straight lines.

south of the cold tongue. In contrast, the mean gradient of the wind stress magnitude is nearly symmetric about the cold tongue. The ratio of $|(\boldsymbol{\nabla}|\boldsymbol{\tau}|)|$ to $|\boldsymbol{\nabla} T|$ is thus about twice as large on the south side of the cold tongue. The asymmetry in the mean SST gradient results in an asymmetry in the magnitudes of the SST gradients in the perturbation SST fields; the mean perturbation SST gradients $\left|\nabla T^{\prime}\right|$ are about twice as large north of the cold tongue as they are south of the cold tongue (cf. Figs. $6 \mathrm{c}$ and $7 \mathrm{c}$ ). The ratio of the amplitude of the cosine angular dependence of $\boldsymbol{\nabla} \cdot \boldsymbol{\tau}^{\prime}$ to the magnitude of the perturbation SST gradient $\left|\boldsymbol{\nabla} T^{\prime}\right|$ is therefore also about twice as large south of the cold tongue. This is a qualitative independent verification of the approximate factor of 2 larger sensitivity of the wind stress divergence south of the cold tongue.

The reason for the asymmetric response of the wind stress divergence on opposite sides of the cold tongue
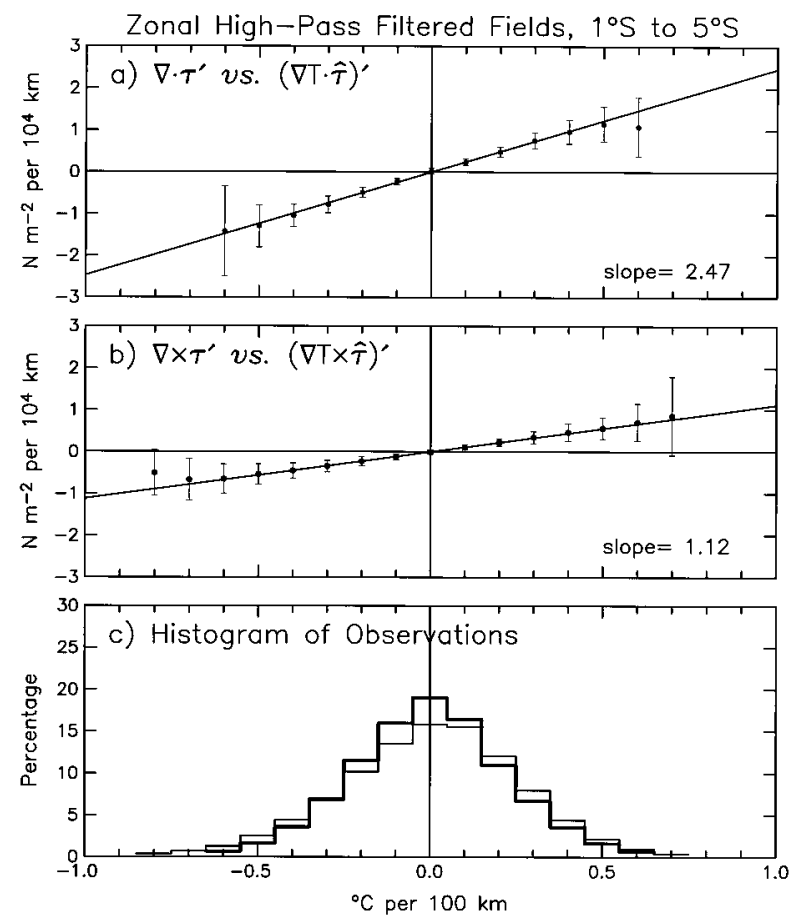

FIG. 11. The same as Fig. 10, except for the zonally high-pass filtered fields in the longitude range $150^{\circ}-100^{\circ} \mathrm{W}$ and latitude range $1^{\circ}-5^{\circ} \mathrm{S}$ on the south side of the cold tongue.

is not immediately apparent. One possible explanation is the asymmetric response of atmospheric turbulence to stability changes in stable versus unstable regimes. The Richardson number and other dimensionless measures of turbulent flow characteristics in the surface layer are observed to have a different functional dependence on atmospheric stability in stable and unstable regimes (see discussion by Kraus and Businger 1994). All other things being equal, a local increase in stability under preexisting stable conditions will result in a greater decrease in the magnitude of turbulent vertical transfers of horizontal momentum than an equivalent increase in stability under preexisting unstable conditions. A similar stability dependence of turbulent and convective momentum fluxes is expected above the surface layer as well.

Other local boundary layer effects that might contribute to asymmetry include a difference between the boundary layer depth north and south of the equator and the difference in adjustment timescales due to turbulence and convection for stable and unstable boundary layers. Large-scale dynamics may also contribute to the asymmetry of the atmospheric response to TIWs. The change in sign of the Coriolis force across the cold tongue introduces a fundamental asymmetry for crossequatorial boundary layer flow. The large-scale adjustment processes in cross-equatorial flow have been examined theoretically by Tomas et al. (1999) and others assuming neutral static stability in the atmospheric 
boundary layer. The strong coupling between surface wind stress and SST suggests, however, that more realistic modeling of air-sea interaction processes is needed to model the asymmetric atmospheric response to TIW-induced SST perturbations.

The coupling of the perturbation wind stress curl field to the underlying SST perturbations is significantly different from that of the perturbation wind stress divergence field. In both latitude bands, the binned mean values of the perturbation wind stress curl, $\boldsymbol{\nabla} \times \boldsymbol{\tau}^{\prime} \cdot \hat{\mathbf{k}}$ vary linearly with the perturbation crosswind SST gradient, $(\nabla T \times \hat{\boldsymbol{\tau}})^{\prime} \cdot \hat{\mathbf{k}}$ (Figs. $10 \mathrm{~b}$ and $11 \mathrm{~b}$ ), as expected from the sine dependencies in Fig. 9. The slightly larger sensitivity of the wind stress curl field to lateral SST variations south of the cold tongue than north of the cold tongue is at most only marginally significant, based on the error estimates on the binned values in Figs. 10b and $11 \mathrm{~b}$. However, the sensitivity of the wind stress curl to the crosswind SST gradient is significantly smaller than the sensitivity of the wind stress divergence to the downwind SST gradient (by slightly more than a factor of 2 south of the cold tongue and by slightly less than a factor of 2 north of the cold tongue).

The difference between the strength of the coupling of the wind stress divergence to the downwind SST gradient and the coupling of the wind stress curl to the crosswind SST gradient in the perturbation fields may be attributable to the finite timescale for adjustment of the vertical atmospheric boundary layer structure as the air encounters changes of SST. For a convectively mixed layer, the adjustment timescale is on the order of $h /\left(w_{0}\right.$ $+w_{e}$ ), where $h$ is the boundary layer thickness and $w_{0}$ and $w_{e}$ are velocity scales for thermodynamic fluxes at the surface and mass entrainment at the top of the boundary layer, respectively (Betts 1983). For a surface wind speed of $5 \mathrm{~m} \mathrm{~s}^{-1}$, a boundary layer thickness of $500 \mathrm{~m}$ and a boundary layer divergence of $5 \times 10^{-6}$ $\mathrm{s}^{-1}$, the adjustment time is $\sim 14 \mathrm{~h}$, which corresponds to a horizontal displacement of $\sim 250 \mathrm{~km}$.

For the case of flow across an SST front, the boundary layer must continually adjust to the changing SST in the downwind direction. The vertical structure of the boundary layer therefore cannot reach equilibrium until the flow has passed over the SST front into a region of relatively weak downwind SST gradient. For air blowing from warm to cool water, the convective and turbulent fluxes would be less than their equilibrium values as the boundary layer adjusts to the cooler surface boundary condition. Assuming that convection transports momentum toward the cool sea surface, the surface stress over the increasingly cooler water would be lower than for the case of an equilibrium boundary layer profile. This would result in a horizontal convergence of the surface wind stress across the SST front with decreasing effect downwind. For air blowing from cool to warm water, the turbulent and convective fluxes would be enhanced relative to the equilibrium profile, thus re- sulting in a stronger horizontal divergence of the surface stress across the SST front.

The enhanced convergence and divergence of flow across isotherms can be contrasted with the boundary layer response for flow along an SST front. In this case, the weak downwind SST gradient along the trajectory of a given air parcel may allow sufficient time for the boundary layer to come into equilibrium with the SST. As a consequence, the wind stress curl along the SST front may be weaker than for the nonequilibrated case. The finite timescale of boundary layer adjustment may therefore explain the weaker response of wind stress curl to the crosswind SST gradient compared with the wind stress divergence response to the downwind SST gradient.

Another factor that could contribute to the difference between the coupling strength of wind stress divergence and curl to the SST gradient field is the effect of ocean surface currents on the wind stress. The observations of upper-ocean velocity by Kennan and Flament (2000) indicate that the surface velocity to the north of the SST front is approximately parallel to isotherms, thus forming anticyclonic vortices between successive TIW cusps. From the survey of a single vortex, they observed ocean surface velocities of $0.5-1.0 \mathrm{~m} \mathrm{~s}^{-1}$ near the SST front. Scatterometers measure wind stress relative to the ocean surface velocity. Since the ocean surface velocity is approximately parallel to isotherms, the cross-isotherm component of the wind stress is unaffected by the ocean surface velocity. However, the along-isotherm component of the wind stress decreases when the alongwind component of ocean surface velocity is in the same direction as the wind. The wind stress divergence and curl respond to the cross-isotherm and along-isotherm components of the wind stress, respectively. The distinction between the effects of ocean surface velocity on the cross-isotherm and along-isotherm components of the wind stress would therefore be expected to have different effects on the wind stress divergence and curl.

Without direct observations of the ocean surface velocity coincident with the wind observations, it is not possible to quantify the magnitude of the effect of ocean surface velocity on the wind stress. However, since TIW-induced ocean surface velocity perturbations of $0.5-1.0 \mathrm{~m} \mathrm{~s}^{-1}$ are a substantial fraction of the $\sim 2 \mathrm{~m} \mathrm{~s}^{-1}$ perturbations of the wind speeds in this region, it would not be surprising to find that the wind stress curl response to the crosswind SST gradient is significantly affected by the ocean surface velocity. Because the wind is in the same direction as the ocean surface velocity in the regions where TIW-induced wind stress curl perturbations are large (see Fig. 4 and compare with the ocean surface velocity field presented by Kennan and Flament 2000), the ocean surface velocity effect would reduce the wind stress curl response, as is observed from the QuikSCAT and TMI data.

The couplings between the derivative wind stress fields and the SST gradient field in Figs. 10 and 11 were 

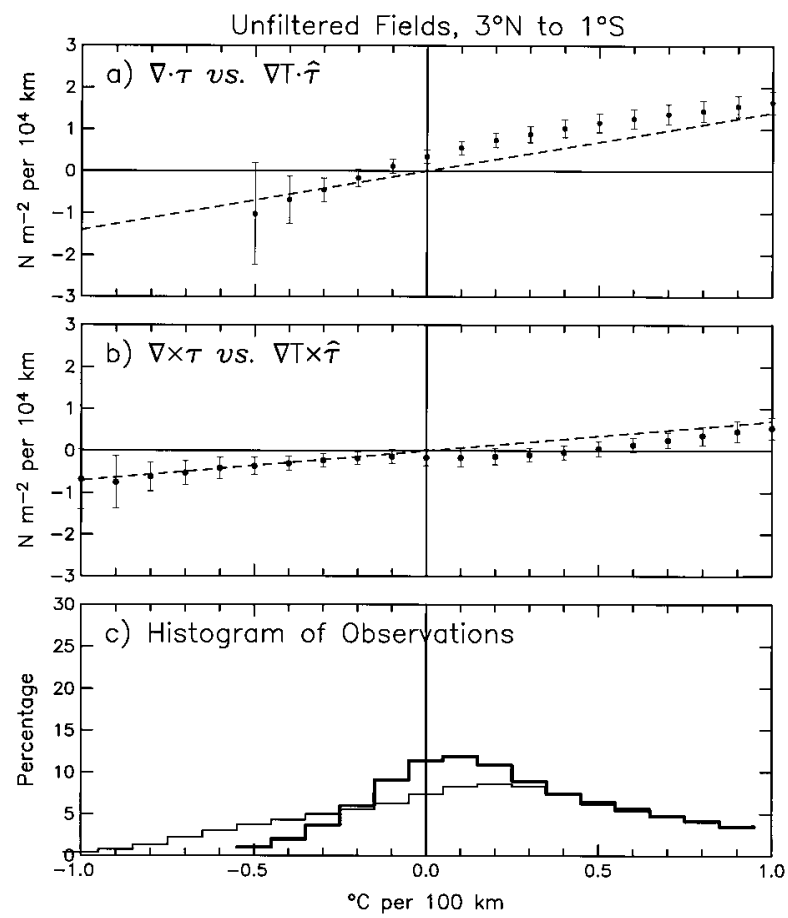

FIG. 12. The same as Fig. 10, except for the unfiltered SST and wind stress fields in the longitude range $150^{\circ}-100^{\circ} \mathrm{W}$ and the latitude range $3^{\circ} \mathrm{N}-1^{\circ} \mathrm{S}$ on the north side of the cold tongue. The dashed lines correspond to the coupling coefficients between the northern perturbation fields shown in Fig. 10.

deduced from the zonally high-pass filtered wind stress and SST fields. The applicability of these coupling coefficients (the slopes of the least squares fit lines in Figs. 10 and 11) to the unfiltered wind stress and SST fields is shown in Figs. 12 and 13. The dashed lines correspond to the least squares fit straight lines from Figs. 10 and 11 . The solid circles are the binned mean values of the unfiltered wind stress divergence (Figs. 12a and 13a) and unfiltered wind stress curl (Figs. 12b and 13b), plotted as functions of the unfiltered downwind and crosswind SST gradients, respectively.

On the south side of the cold tongue (Fig. 13), it is apparent that the linear relationships deduced from the zonally high-pass filtered fields are closely reproduced in the unfiltered wind stress and SST fields. On the north side of the cold tongue, however, the agreement between the binned mean values of the unfiltered wind stress divergence and curl and the linear relationships deduced from the zonally high-pass filtered fields is not as good (Fig. 12). In the region of positive downwind SST gradients near the northern SST front, the coupling coefficient for the wind stress divergence deduced from the perturbation fields underestimates the wind stress divergence by roughly a constant value of about $0.3 \mathrm{~N}$ $\mathrm{m}^{-2}\left(10^{4} \mathrm{~km}\right)^{-1}$. Similarly, the coupling coefficient for the wind stress curl overestimates the wind stress curl by roughly the same amount near the northern SST front.
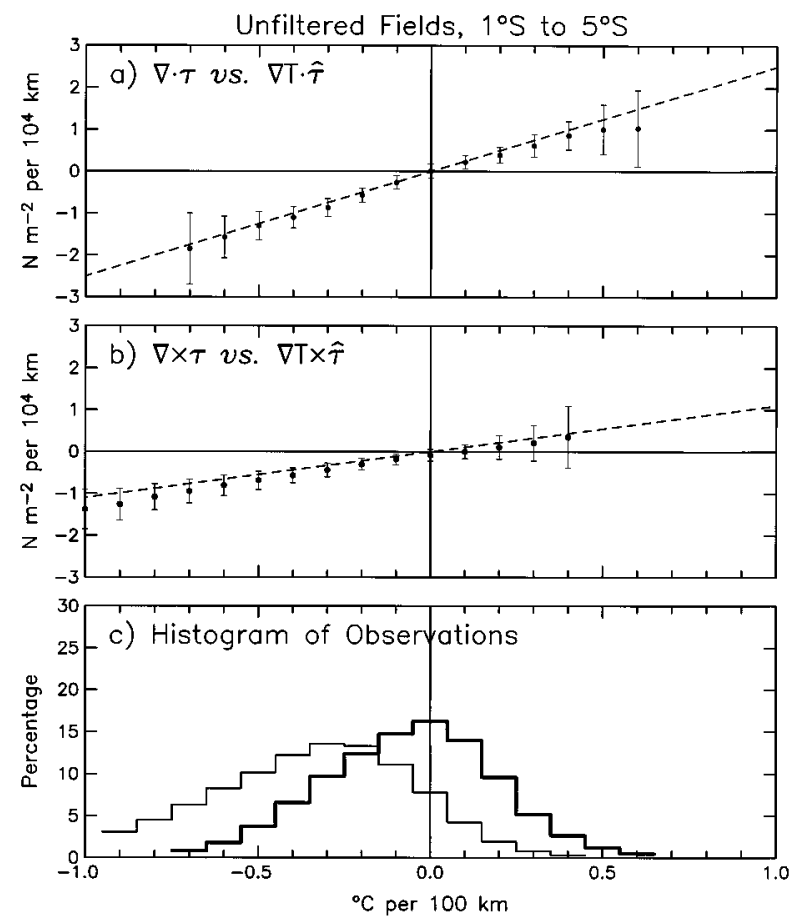

FIG. 13. The same as Fig. 11, except for the unfiltered SST and wind stress fields in the longitude range $150^{\circ}-100^{\circ} \mathrm{W}$ and the latitude range $1^{\circ}-5^{\circ} \mathrm{S}$ on the south side of the cold tongue. The dashed lines correspond to the coupling coefficients between the southern perturbation fields shown in Fig. 11.

The misfits of the predicted wind stress divergence and curl responses to SST gradients in the unfiltered fields north of the cold tongue are likely an indication of processes other than SST modification of boundary layer stability that may affect the wind stress field. For example, this may be evidence of the importance of northward acceleration from the SST-induced pressure gradient force on the north side of the cold tongue, which has been discussed by Lindzen and Nigam (1987), Mitchell and Wallace (1992), Young (1987), and Tomas et al. (1999). These other processes are evidently either of secondary importance in generating TIW-related wind stress perturbations or have large zonal scale and are therefore eliminated by the zonal high-pass filtering applied to highlight TIW-related variability in Figs. 10 and 11.

\section{Westward propagation}

The case study maps in Fig. 4 and the 3-month statistics in Figs. 8-11 strongly suggest a phase locking between the perturbed derivative wind stress fields (divergence and curl) and the perturbed underlying SST field as the TIWs propagate westward. This is verified in Figs. 14 and 15 from time-longitude plots along $1^{\circ} \mathrm{N}$ and $3^{\circ} \mathrm{S}$ that bracket the cold tongue in the eastern tropical Pacific. Synchronized westward propagation is evident in all of the quantities. Contours of the perturbation 
$T^{\prime}$

$1^{\circ} \mathrm{N}$

a)

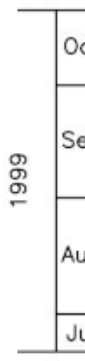

$=$

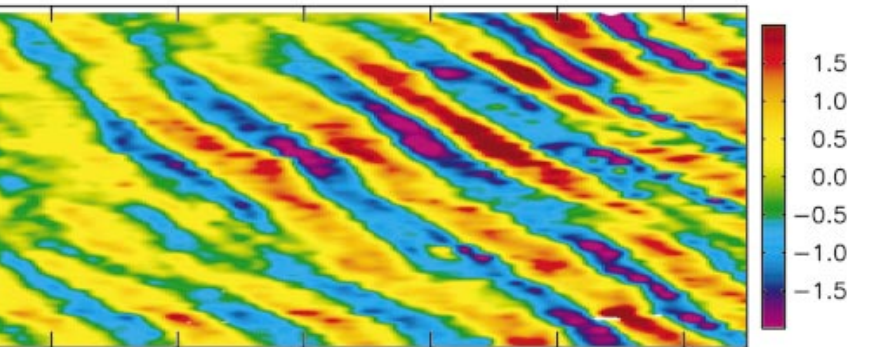

$\left|\tau^{\prime}\right|$ with contours of $T^{\prime}$
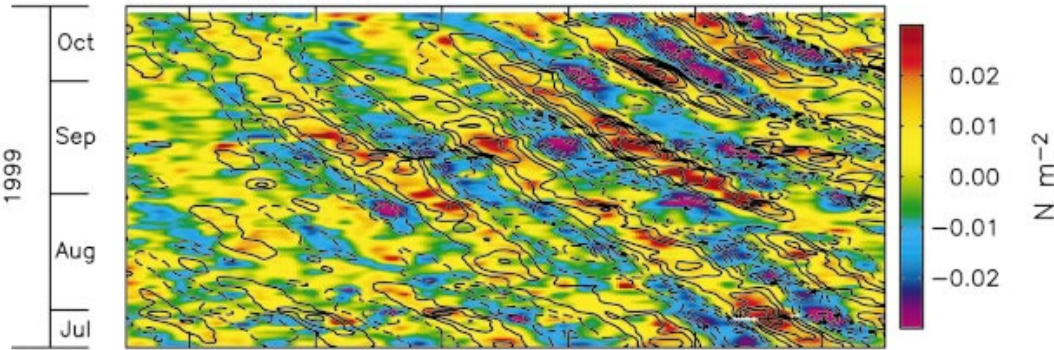

$\nabla \cdot \tau^{\prime}$ with contours of $(\nabla \mathrm{T} \cdot \hat{\tau})^{\prime}$
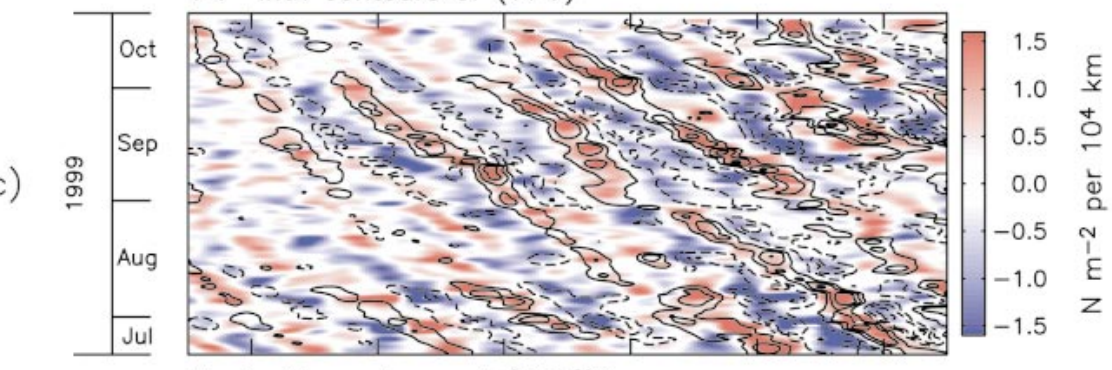

$\nabla \times \tau^{\prime}$ with contours of $(\nabla T \times \hat{\tau})^{\prime}$

d) $\stackrel{\circ}{\stackrel{\circ}{\circ}}{ }^{\mathrm{Se}}$
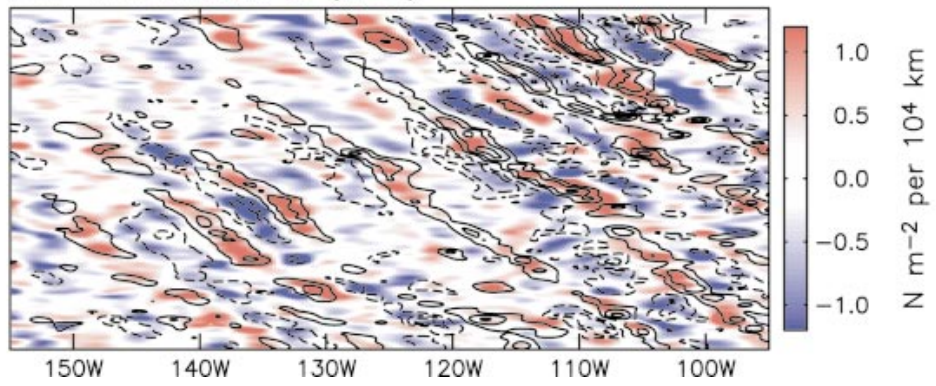

FIG. 14. Time-longitude plots along $1^{\circ} \mathrm{N}$ on the north side of the cold tongue showing zonally high-pass filtered SST and wind stress fields: (a) perturbation SST; (b) perturbation wind stress magnitude with contours of perturbation SST overlaid; (c) perturbation wind stress divergence with contours of the perturbation downwind SST gradient, $(\nabla T \cdot \hat{\tau})^{\prime}$, overlaid; and (d) perturbation wind stress curl with contours of the perturbation crosswind SST gradient, $(\nabla T \times \hat{\boldsymbol{\tau}})^{\prime} \cdot \hat{\mathbf{k}}$, overlaid. Contour intervals are $0.5^{\circ} \mathrm{C}$ in (b) and $0.4^{\circ} \mathrm{C}(100 \mathrm{~km})^{-1}$ in (c) and (d). For clarity, zero contours have been omitted from (b) to (d).

downwind and crosswind SST gradients are overlaid on the color plots of perturbation wind stress divergence and perturbation wind stress curl in Figs. 14c,d and $15 \mathrm{c}, \mathrm{d}$. The phase relationships between the components of the SST gradient and the derivative wind stress fields are seen to be consistent across longitude and time with the couplings deduced statistically from Figs. 10 and 11 .
Along the northern SST front (Fig. 14), the characteristics of the westward-propagating TIWs are very similar to those reported by Chelton et al. (2000) for the 1998-99 TIW season. During the time period considered here, the propagation was quite regular east of about $140^{\circ} \mathrm{W}$ with a westward phase speed of about 0.6 $\mathrm{m} \mathrm{s}^{-1}$. This is somewhat faster than the $0.53 \mathrm{~m} \mathrm{~s}^{-1}$ estimated by Chelton et al. (2000), but the difference 
$T^{\prime}$

$3^{\circ} \mathrm{S}$

a)

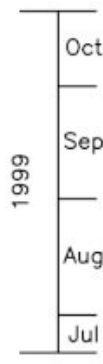

$T^{\prime}$

395

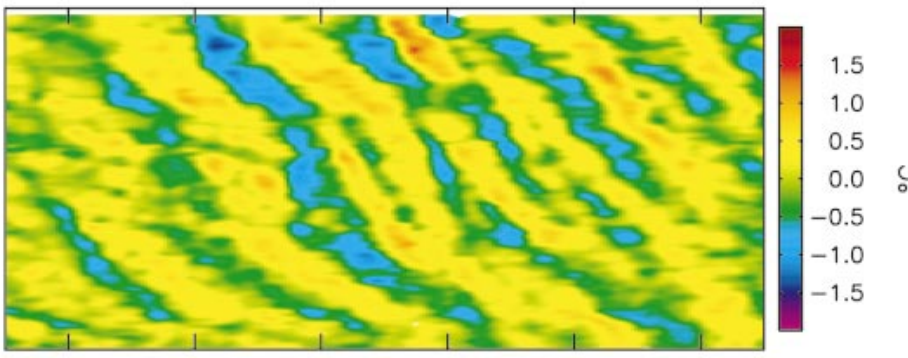

$\left|\tau^{\prime}\right|$ with contours of $T^{\prime}$

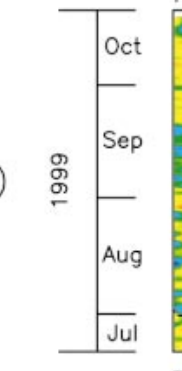

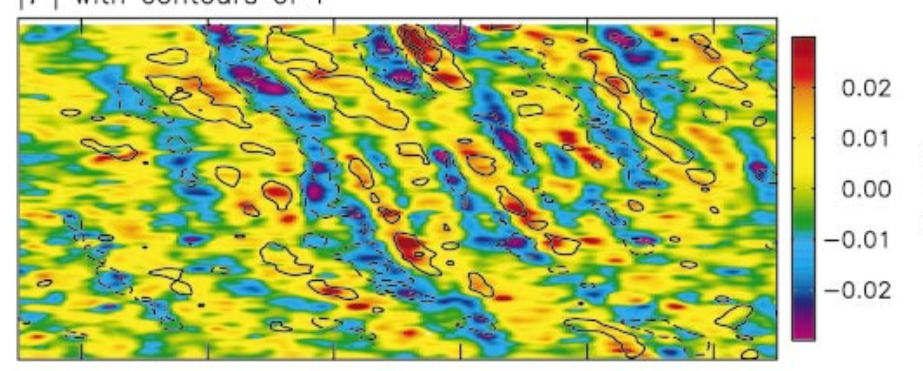

$\stackrel{\substack{\text { N } \\ \mathrm{z}}}{\mathrm{N}}$

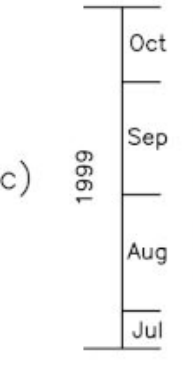

$\nabla \cdot \tau^{\prime}$ with contours of $(\nabla T \cdot \hat{\tau})^{\prime}$

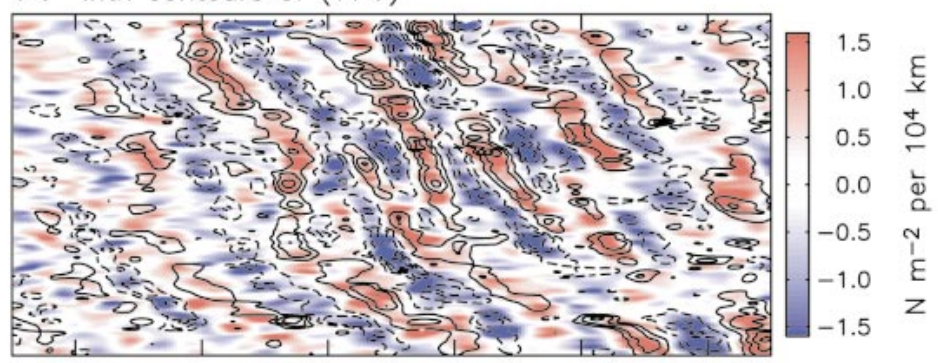

$\nabla \times \tau^{\prime}$ with contours of $(\nabla T \times \hat{\tau})^{\prime}$

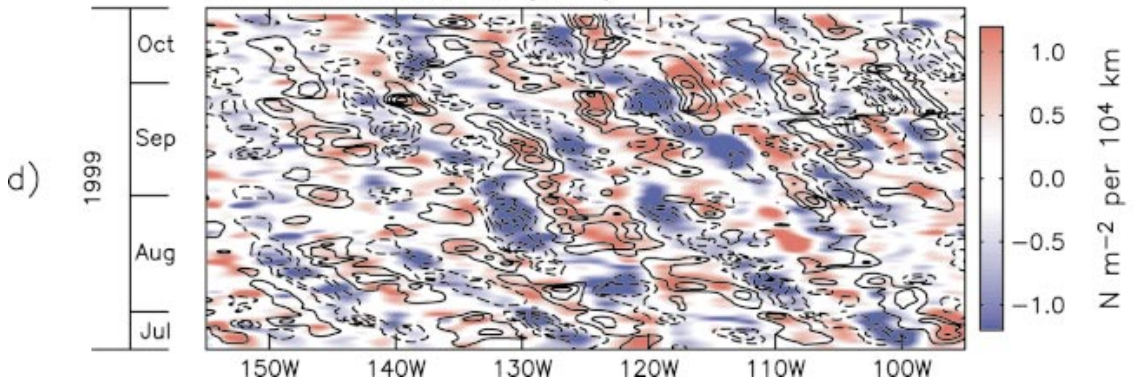

FIG. 15. The same as Fig. 14, except time-longitude plots of zonally high-pass filtered SST and wind stress fields along $3^{\circ} \mathrm{S}$ on the south side of the cold tongue. In order to reveal the weaker signals south of the equator, the contour intervals are half those used in Fig. 14.

could easily be explained by the larger uncertainty of the phase speed estimated from the short 3-month data record analyzed here or it could be due to small temporal variations of the kinematic properties of the TIWs. In this regard, an interesting feature of Fig. 14 is the change in the westward phase speed west of about $140^{\circ} \mathrm{W}$ that occurred in late August. This is apparent in the SST, wind stress magnitude, and wind stress divergence fields (Figs. 14a-c), as well as in the contours of the downwind SST gradient overlaid on Fig. 14c. The wind stress curl and crosswind SST gradient at these longitudes (Fig. 14d) were too weak for the change of phase speed to be clearly seen.

Along the southern SST front (Fig. 15), the characteristics of westward propagation were very different. During the first month of the data record, the southern TIWs propagated westward at about the same $0.6 \mathrm{~m} \mathrm{~s}^{-1}$ phase speed observed along $1^{\circ} \mathrm{N}$. In mid-August, the phase speed abruptly decreased to only about $0.25 \mathrm{~m}$ $\mathrm{s}^{-1}$. The phase speed appears to have increased again in early October. These irregularities are surprising in view of the fact that Chelton et al. (2000) found $\sim 0.5$ 
$\mathrm{m} \mathrm{s}^{-1}$ westward propagation on both sides of the equatorial cold tongue throughout the 1998-99 TIW season. The reason for the abrupt changes in the westward phase speed along $3^{\circ} \mathrm{S}$ during the 3 -month period analyzed here is not yet known. These features of the westward propagation are reproduced coherently in the perturbation SST, wind stress magnitude, wind stress divergence, and wind stress curl fields along the southern SST front. Moreover, as in the case of propagation along the northern SST front in Fig. 14, the contours of the perturbation downwind and crosswind SST gradients in Figs. $15 \mathrm{c}$ and $15 \mathrm{~d}$, respectively, are phase locked with the perturbation wind stress divergence and curl in the manner deduced statistically from Figs. 10 and 11 .

The close coupling between the wind stress field and the underlying SST field along $3^{\circ} \mathrm{S}$ is further illustrated by the splitting of the westward-propagating SST signal into two separate warm perturbations from mid-August to mid-September between $120^{\circ}$ and $130^{\circ} \mathrm{W}$. This splitting is also apparent in the perturbation wind stress divergence field and in the associated perturbation downwind SST gradient (Fig. 15c). Interestingly, the splitting is not clearly evident in the perturbation wind stress curl field in Fig. 15d. However, consistent with the statistical relation in Fig. 11b, the splitting is also not clearly evident in the associated perturbation crosswind SST gradient.

The distinctly different characteristics of the westward propagation along $1^{\circ} \mathrm{N}$ and $3^{\circ} \mathrm{S}$ are intriguing. The 3 -month data record analyzed here is too short to examine this in detail. This can be investigated further as the QuikSCAT and TMI data records continue to accumulate so that the westward propagation of the SST signatures of TIWs can be compared and contrasted for the 1998-99 and 1999-2000 TIW seasons.

\section{Discussion and conclusions}

The satellite microwave measurements of surface wind stress and SST during the 3-month period 21 July20 October 1999 analyzed here provide definitive observational evidence of ocean-atmosphere coupling in the eastern tropical Pacific. The southeastern Pacific trade winds blow northwestward toward the oceanic equatorial cold tongue. The atmospheric boundary layer is stabilized by the cooler water. As first hypothesized by Wallace et al. (1989) from analysis of climatological average wind and SST fields, this decouples the surface winds from the winds aloft and decreases the surface winds, thus resulting in a convergence of the surface wind stress. As the low-level winds cross isotherms on the north side of the cold tongue, the atmospheric boundary layer is destabilized over the warmer water and the enhanced turbulent mixing of momentum from aloft increases the surface winds, resulting in a divergence of the surface wind stress.

TIW-induced perturbations of the SST fronts that bracket the equatorial cold tongue allow a detailed in- vestigation of the structure of the SST-induced modification of the surface wind stress and its dependence on the orientation of the wind stress relative to perturbations of the SST gradient vector. The perturbation wind stress divergence varies linearly with the perturbation downwind component of the SST gradient. Convergence and divergence are thus locally strongest where the wind blows parallel to the SST gradient (perpendicular to isotherms). The perturbation wind stress curl varies linearly with the perturbation crosswind component of the SST gradient. In regions where the angle between the wind direction and the SST gradient is oblique, a wind stress curl thus develops from lateral variations of the SST-induced changes of the surface wind stress. The wind stress curl is locally strongest where the winds blow perpendicular to the SST gradient (parallel to isotherms).

The observed couplings of the derivative wind stress fields to the perturbation downwind and crosswind SST gradients are completely consistent with the SST-induced modifications of atmospheric stability hypothesized by Wallace et al. (1989). Other dynamical mechanisms such as pressure gradient forcing as suggested by Lindzen and Nigam (1987), Mitchell and Wallace (1992), Young (1987), and Tomas et al. (1999) are evidently of secondary importance, at least in terms of SST effects on surface winds on the time- and space scales of TIWs. On larger scales, the pressure gradient forcing may be more important (see Figs. 12 and 13).

The apparent strong and rapid atmospheric response to TIW-induced perturbations of the SST field suggests that ocean-atmosphere coupling plays an important role in the thermodynamics of TIWs. The SST perturbations modify the atmospheric boundary layer in such a way as to induce negative thermodynamic feedback on the TIWs. Since the perturbed wind stress and SST fields propagate westward in synchronization with the TIWs, the high winds over warm water between successive cold cusps result in continuous upper-ocean heat loss through surface evaporation (Zhang and McPhaden 1995). In addition, the enhanced vertical mixing over the warmer water generates increased low-level cloudiness that reduces the solar insolation that reaches the sea surface (Deser et al. 1993). It has been estimated that the cooling by the combined effects of these two components of ocean-atmosphere heat flux may be as large as $\sim 0.5^{\circ} \mathrm{C}$ per month (Deser et al. 1993; McPhaden 1996).

The high space-time resolution afforded by QuikSCAT measurements of surface wind stress also reveals a strong dynamical feedback on the TIWs. The orientation of the wind stress relative to the isotherms along the cuspy northern SST front generates very strong positive perturbations of the wind stress curl that drives the ocean circulation. There is also a broad band of negative wind stress curl south of the equator with local intensification in regions where the wind blows parallel to TIW-induced perturbations of the weaker southern SST 
21 July - 20 October 1999

a) QuikSCAT Average Wind Stress Divergence

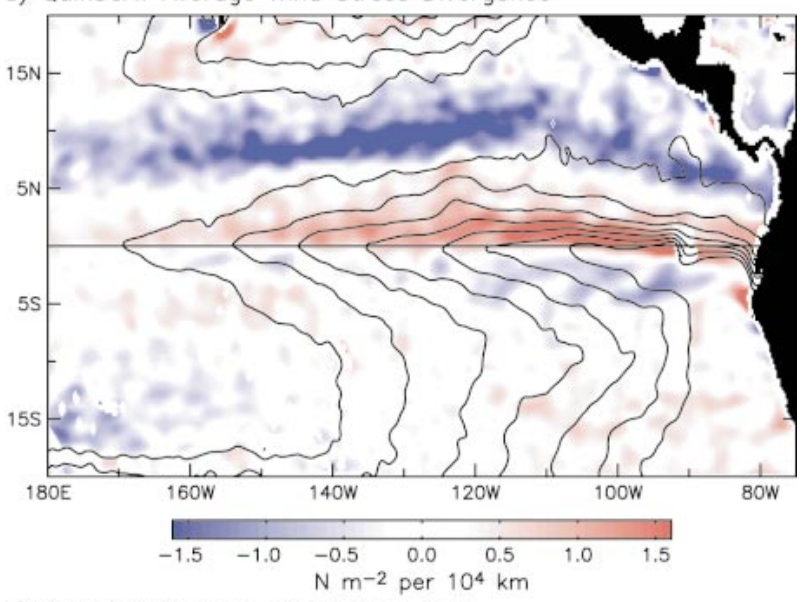

b) QuikSCAT Average Wind Stress Curl

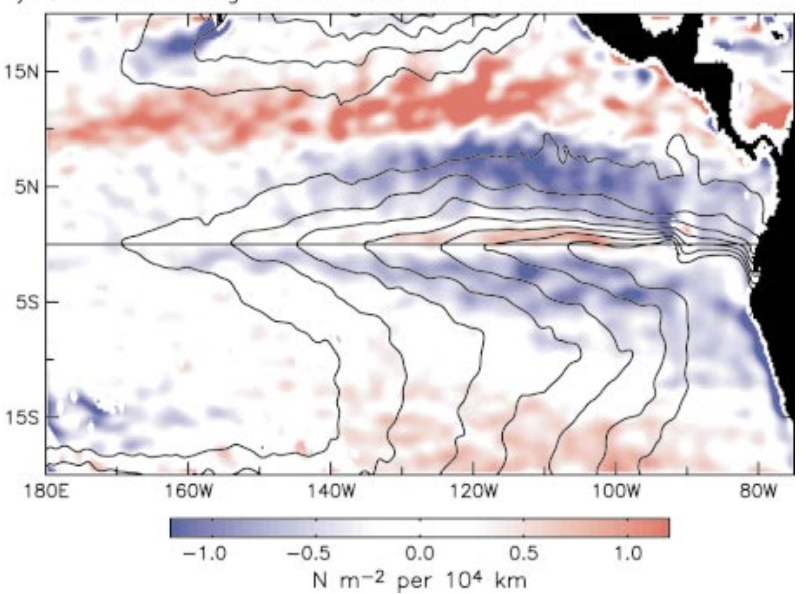

FIG. 16. Three-month averages (21 July-20 October 1999) over $4^{\circ}$ of longitude by $2^{\circ}$ of latitude constructed from QuikSCAT measurements of wind stress: (a) wind stress divergence; and (b) wind stress curl. Contours correspond to isotherms from Fig. 1a at intervals of $1^{\circ} \mathrm{C}$ between $21^{\circ}$ and $27^{\circ} \mathrm{C}$.

front. A zonal band of strong wind stress divergence just north of the equator is also noteworthy. Without a theoretical analysis, which is beyond the scope of this study, the nature of the feedback of these wind stress curl and divergence patterns on TIWs is less clear than the simple negative thermodynamic feedback discussed above. Given the intensity of the wind stress curl and divergence perturbations and the fact that the locations of strongest wind stress curl and divergence propagate west in synchronization with the TIWs, there can be no doubt that these perturbation wind forcings must be taken into consideration in determining the dynamics and energetics of TIWs, and therefore in assessing the impact of TIWs on the large-scale momentum and heat budgets of the eastern tropical Pacific.

The ocean-atmosphere coupling demonstrated here is also important on scales much larger than those associated with TIW variability. Large-scale ocean circu- lation outside of the equatorial waveguide is driven by the wind stress curl. The broad band of negative wind stress curl on the south side of the cold tongue, as well as the narrow band of positive wind stress curl just north of the equator in the 3-month average shown in Fig. $16 \mathrm{~b}$ are direct responses of the wind stress to the underlying SST field. The southern trade winds blow approximately parallel to the isotherms in the broad timeaveraged southern SST front (Fig. 1), resulting in the broad band of strong wind stress curl south of the cold tongue. Likewise, the wind stress blows at an oblique angle across the isotherms along the narrow northern SST front, resulting in the narrow bands of positive wind stress curl and divergence along the time-averaged SST front on the north side of the cold tongue. The zonal band of positive wind stress curl is definitive evidence for the importance of the Wallace et al. (1989) mechanism for SST modification of the surface wind field; the pressure gradient mechanism suggested by Lindzen and Nigam (1987) and others could not produce the lateral shear of the wind necessary to create this wind stress curl.

To the north of about $3^{\circ} \mathrm{N}$, the band of convergence in the ITCZ and the bands of negative and positive wind stress curl on the south and north sides of the ITCZ, respectively, (see Fig. 16b) are evidently associated with processes distinct from the SST modification of atmospheric boundary layer stability considered in this study. However, these features of the wind stress curl field are important to wind-forced ocean circulation in the Tropics. The intensities of the banded structures of the wind stress curl and divergence fields are considerably underestimated and their narrow meridional scales are poorly resolved in wind stress curl and divergence fields constructed from all other sources of surface wind information (e.g., Rienecker et al. 1996).

The meteorological significance of the SST-induced modifications of the surface wind field on deeper atmospheric circulations in the vicinities of the cold tongue and ITCZ is less clear without measurements of the winds aloft. The analysis of Wallace et al. (1989) and the results of this study suggest that the band of wind stress divergence north of the cold tongue and the associated band of wind stress convergence south of the cold tongue in the 3-month average shown in Fig. 16a are direct responses to SST-induced modification of the surface wind field. Deser and Wallace (1990) and Mitchell and Wallace (1992) have noted that the intensities of the equatorial cold tongue and cross-equatorial winds in the band between the equator and about $8^{\circ} \mathrm{N}$ are highly correlated with variations in the intensity and latitude of the ITCZ. It is thus possible that the SST-induced surface wind stress features are part of the deep meridional overturning of the Hadley-type circulation over the eastern Pacific.

Alternatively, the impacts of the surface divergence field implied by the QuikSCAT data may be confined to the atmospheric boundary layer. The modeling results 
21 July - 20 October 1999

a) QuikSCAT Average Zonal Wind Stress

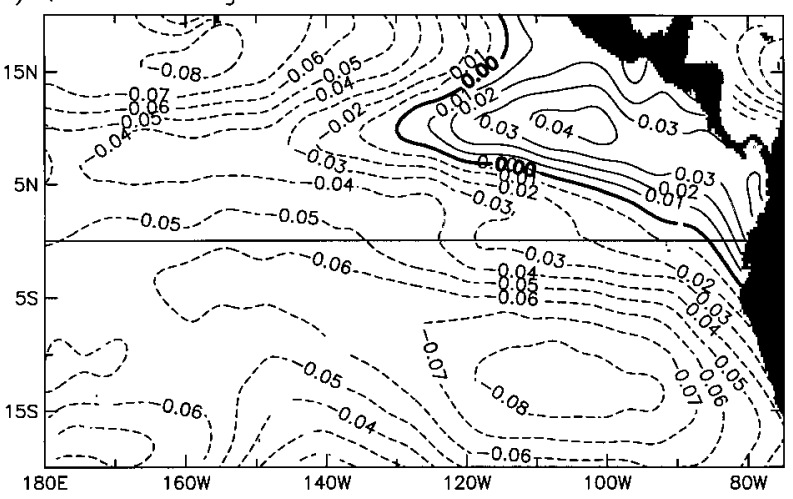

b) QuikSCAT Average Meridional Wind Stress

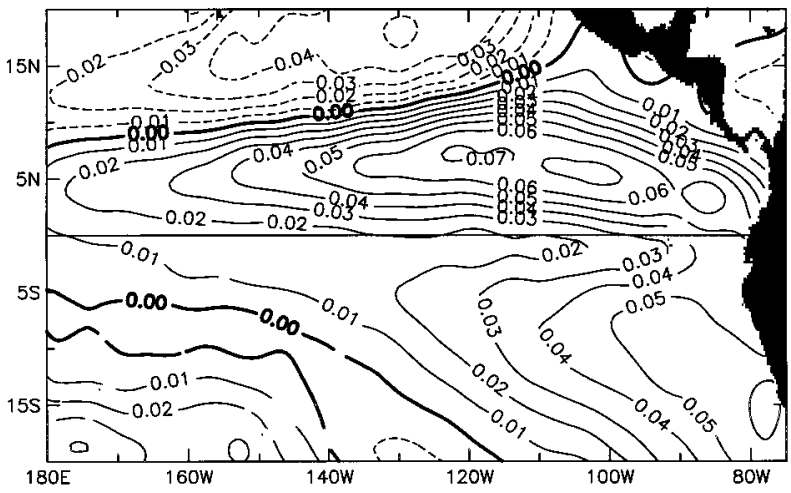

Fig. 17. Three-month averages (21 July-20 October 1999) over $4^{\circ}$ of longitude by $2^{\circ}$ of latitude constructed from QuikSCAT observations: (a) the zonal component of wind stress; and (b) the meridional component of wind stress. Contour interval is $0.01 \mathrm{~N} \mathrm{~m}^{-2}$ and negative contours are shown as dashed lines in both panels.

of Xie et al. (1998) and a recent analysis of QuikSCAT, TMI, and SSM/I data by Hashizume et al. (2001) suggest that the TIW-induced perturbations may penetrate several kilometers above the sea surface and may even weakly perturb the ITCZ. The intensity of the zonal bands of divergence and convergence in Fig. 16a warrant further modeling studies and an in situ observational field program to investigate the vertical structure of the wind field in order to quantify the relationship between the SST-induced modification of the atmospheric boundary layer and the atmospheric circulation aloft.

The observed geographical structure of the surface wind stress field (Fig. 1b) raises important questions about coupled ocean-atmosphere interaction in the eastern tropical Pacific. Equatorial upwelling from Ekman divergence at the equator forced by the zonal component of wind stress that is generally believed to play a role in the existence of cold water along the equator cannot explain the observed equatorial asymmetry and meridional scale of the cold tongue. Indeed, between the South American coastline and about $120^{\circ} \mathrm{W}$, it is evident from
Fig. 17a that the zonal component of wind stress is very weak within the equatorial waveguide.

Mitchell and Wallace (1992) found that seasonal variations of the intensity of the equatorial cold tongue are much more highly correlated with the meridional wind stress than with the zonal wind stress. They hypothesized that this is because of a positive feedback in which the northern SST front accelerates the winds north of the cold tongue and that these northward winds generate upwelling of cold water just south of the equator, thereby sustaining the cold tongue that causes the winds to accelerate across the SST front. There is some modeling evidence to support this speculation. Cane (1979) and Philander (1990, section 4.8.2) showed that the ocean response to uniform northward wind generates upwelling south of the equator, which may explain why the cold tongue is centered south of the equator. Philander and Pacanowski (1981) suggested that this upwelling originates as coastal upwelling along the eastern boundary at low latitudes in the Southern Hemisphere and then spreads rapidly westward by a combination of advection and Rossby wave propagation.

It is noteworthy that the numerical studies by Cane (1979) and Philander and Pacanowski (1981) both considered the ocean response to the sudden onset of steady, uniform meridional winds. It is evident from Fig. 1b that this simple pattern of spatially uniform northward wind stress is a highly idealized representation of the actual wind field. The nonuniformity of the meridional wind stress in the QuikSCAT observations is more clearly seen in Fig. 17b. The SST-induced modification of the overlying wind stress results in more than a factor of 2 reduction of the northward component of wind stress over the equatorial cold tongue. North of the cold tongue, the northward component of wind stress increases by more than a factor of 3 . A realistic simulation of the cold tongue response to wind forcing must take into consideration this large latitudinal variation of the meridional wind stress field.

The QuikSCAT observations also clearly show the very inhomogeneous structure of the zonal component of the wind stress field (Fig. 17a). East of about $130^{\circ} \mathrm{W}$, the zonal wind stress is very weak over the cold tongue as noted above and is highly asymmetric about the equator. On the south side of the cold tongue, maximum easterly winds occur at about $12^{\circ} \mathrm{S}$. The easterly component of wind stress decreases to a local minimum over the cold tongue and then increases slightly just north of the cold tongue before decreasing again and then turning westerly at higher latitudes. The maximum westerly winds occur at about $8^{\circ} \mathrm{N}$.

The combined patterns of the zonal and meridional components of the wind stress in Fig. 17 create the banded structure of the wind stress curl and divergence fields discussed above (Fig. 16). As noted previously, the observed structures of the wind stress curl and divergence fields are poorly represented in all other sources of surface wind information. The intensities of the 
wind stress curl and divergence patterns strongly suggest that both components of the surface wind stress field must be taken into consideration when investigating the wind-driven circulation throughout the eastern tropical Pacific (even close to the equator). There is clearly a need for additional modeling studies that consider the eastern tropical Pacific ocean response to more realistic wind forcing, including the effects of the wind stress curl and divergence.

The ocean-atmosphere interaction demonstrated from the QuikSCAT and TMI data also emphasizes the necessity of including stability-dependent boundary layer effects for realistic coupled ocean-atmosphere modeling of the eastern tropical Pacific. This presents challenges for simplified theoretical models of the coupled system. It is possible that the effects of these boundary layer processes are not adequately represented even in comprehensive coupled general circulation models. Mechoso et al. (1995) have shown that these models are not able to reproduce the observed climatological structure of eastern Pacific SST patterns. The equatorial cold tongues in these models tend to be too strong, too restricted latitudinally, and extend too far to the west. The warm pool region to the north of the cold tongue is poorly simulated and varies significantly between different models. In addition, the simulated temperatures south of the cold tongue tend to be warmer than is observed. These systematic errors may be due in part to errors in the wind stress, wind stress divergence, and wind stress curl fields owing to inadequate representation of the strong ocean-atmosphere coupling revealed by the QuikSCAT observations of wind stress and TMI observations of SST.

Acknowledgments. We thank Greg Johnson and Shang-Ping Xie for helpful discussions and comments on the manuscript. The research presented in this paper was supported by Contracts 957580 and 959351 from the Jet Propulsion Laboratory funded under the NSCAT Announcement of Opportunity, NASA Grant NAS532965 for funding of Ocean Vector Winds Science Team activities, NOAA Grant NA96GP0368 from the Office of Global Programs, NASA TRMM Contract NAS59919, NASA's Earth Science Information Partnership through Contract SUB1998-101 from the University of Alabama in Huntsville and NOAA's Office of Oceanic and Atmospheric Research.

\section{REFERENCES}

Baturin, N. G., and P. P. Niiler, 1997: Effects of instability waves in the mixed layer of the equatorial Pacific. J. Geophys. Res., 102, 27 771-27 793.

Betts, A. K., 1983: Thermodynamics of mixed stratocumulus layers: Saturation point budgets. J. Atmos. Sci., 40, 2655-2670.

Bond, N. A., 1992: Observations of planetary boundary layer structure in the eastern equatorial Pacific. J. Climate, 5, 699-706.

Bryden, H., and E. C. Brady, 1989: Eddy momentum and heat fluxes and their effects on the circulation of the equatorial Pacific Ocean. J. Mar. Res., 47, 55-79.

Cane, M. A., 1979: The response of an equatorial ocean to simple wind stress patterns: II. Numerical results. J. Mar. Res., 37, 253 299.

Chelton, D. B., F. J. Wentz, C. L. Gentemann, R. A. de Szoeke, and M. G. Schlax, 2000: Microwave SST observations of transequatorial tropical instability waves. Geophys. Res. Lett., 27, 1239-1242.

Cox, M., 1980: Generation and propagation of 30-day waves in a numerical model of the Pacific. J. Phys. Oceanogr., 10, 11681186.

Deser, C., and J. M. Wallace, 1990: Large-scale atmospheric circulation features of warm and cold episodes in the tropical Pacific. J. Climate, 3, 1254-1281.

- J. J. Bates, and S. Wahl, 1993: The influence of sea surface temperature gradients on stratiform cloudiness along the equatorial front in the Pacific Ocean. J. Climate, 6, 1172-1180.

Dickinson, S., K. A. Kelly, M. J. Caruso, and M. J. McPhaden, 2001: A note on comparisons between the TAO buoy and NASA scatterometer wind vectors. J. Atmos. Oceanic Technol., in press.

Fairall, C. W., E. F. Bradley, D. P. Rogers, J. B. Edson, and G. S. Young, 1996: Bulk parameterization of air-sea fluxes for Tropical Ocean-Global Atmosphere Coupled-Ocean Atmosphere Response Experiment. J. Geophys. Res., 101, 3747-3764.

Flament, P. J., S. C. Kennan, R. A. Knox, P. P. Niiler, and R. L. Bernstein, 1996: The three-dimensional structure of an upper ocean vortex in the tropical Pacific Ocean. Nature, 383, 610 613.

Freilich, M. H., and R. S. Dunbar, 1999: The accuracy of the NSCAT1 vector winds: Comparisons with National Data Buoy Center buoys. J. Geophys. Res., 104, 11 231-11 246.

, D. G. Long, and M. W. Spencer, 1994: SeaWinds: A scanning scatterometer for ADEOS II-Science overview. Proc. Int. Geosci. Remote Sens. Symp., Vol. II, Pasadena, CA, IEEE No. 94CH3378-7, 960-963.

Goldenberg, S. B., and J. J. O'Brien, 1981: Time and space variability of tropical Pacific wind stress. Mon. Wea. Rev., 109, 1190-1207.

Grassl, H., 1976: The dependence of the measured cool skin of the ocean on wind stress and total heat flux. Bound.-Layer Meteor., 10, 465-474.

Hansen, D. V., and C. A. Paul, 1984: Genesis and effects of long waves in the equatorial Pacific. J. Geophys. Res., 89, 10 43110440 .

Hashizume, H., S.-P. Xie, W. T. Liu, and K. Takeuchi, 2001: Local and remote atmospheric response to tropical instability waves: A global view from space. J. Geophys. Res., in press.

Hayes, S. P., M. J. McPhaden, and J. M. Wallace, 1989: The influence of sea-surface temperature on surface wind in the eastern equatorial Pacific: Weekly to monthly variability. J. Climate, 2, 15001506.

Kennan, S. C., and P. J. Flament, 2000: Observations of a tropical instability vortex. J. Phys. Oceanogr., 30, 2277-2301.

Kraus, E. B., and J. A. Businger, 1994: Atmosphere-Ocean Interaction. Oxford University Press, $362 \mathrm{pp}$.

Kummerow, C., W. Barnes, T. Kozu, J. Shiue, and J. Simpson, 1998: The Tropical Rainfall Measuring Mission (TRMM) sensor package. J. Atmos. Oceanic Technol., 15, 808-816.

Large, W. G., and S. Pond, 1981: Open ocean momentum flux measurements in moderate to strong winds. J. Phys. Oceanogr., 11, 324-336.

Legeckis, R., 1977: Long waves in the eastern equatorial Pacific Ocean: A view from a geostationary satellite. Science, 197, $1179-1181$.

Lindzen, R. S., and S. Nigam, 1987: On the role of sea surface temperature gradients in forcing low-level winds and convergence in the tropics. J. Atmos. Sci., 44, 2418-2436.

Luther, D. S., and E. S. Johnson, 1990: Eddy energetics in the upper equatorial Pacific during the Hawaii-to-Tahiti Shuttle Experiment. J. Phys. Oceanogr., 20, 913-944. 
McPhaden, M. J., 1996: Monthly period oscillations in the Pacific North Equatorial Countercurrent. J. Geophys. Res., 101, 63376359.

— observing system: A decade of progress. J. Geophys. Res., 103, 14 169-14 240.

Mechoso, C. R., and Coauthors, 1995: The seasonal cycle over the tropical Pacific in coupled ocean-atmosphere general circulation models. Mon. Wea. Rev., 123, 2825-2838.

Miller, L., D. R. Watts, and M. Wimbush, 1985: Oscillations of dynamic topography in the eastern equatorial Pacific. J. Phys. Oceanogr., 15, 1759-1770.

Mitchell, T. P., and J. M. Wallace, 1992: The annual cycle in equatorial convection and sea surface temperature. J. Climate, 5, 11401156.

Naderi, F. M., M. H. Freilich, and D. G. Long, 1991: Spaceborne radar measurement of wind velocity over the ocean-An overview of the NSCAT scatterometer system. Proc. IEEE, 97, 850866.

Philander, S. G. H., 1978: Instabilities of zonal equatorial currents, Part 2. J. Geophys. Res., 83, 3679-3682.

- 1990: El Niño, La Niña, and the Southern Oscillation. Academic Press, 289 pp.

- , and R. C. Pacanowski, 1981: The ocean response to crossequatorial winds (with application to coastal upwelling in low latitudes). Tellus, 33, 201-210.

Qiao, L., and R. H. Weisberg, 1995: Tropical instability wave kinematics: Observations from the Tropical Instability Wave Experiment. J. Geophys. Res., 100, 8677-8693.

Reverdin, G., C. Frankignoul, E. Kestenare, and M. J. McPhaden, 1994: Seasonal variability in the surface currents of the equatorial Pacific. J. Geophys. Res., 99, 20 323-20 344.

Reynolds, R. W., K. Arpe, C. Gordon, S. P. Hayes, A. Leetmaa, and M. J. McPhaden, 1989: A comparison of tropical Pacific surface wind analyses. J. Climate, 2, 105-111.

Rienecker, M. M., R. Atlas, S. D. Schubert, and C. S. Willett, 1996: A comparison of surface wind products over the North Pacific Ocean. J. Geophys. Res., 101, 1011-1023.
Saunders, P. M., 1967: The temperature at the ocean-air interface. $J$. Atmos. Sci., 24, 269-273.

Schlax, M. G., D. B. Chelton, and M. H. Freilich, 2001: Sampling errors in wind fields constructed from single and tandem scatterometer datasets. J. Atmos. Oceanic Technol., in press.

Swenson, M. S., and D. V. Hansen, 1999: Tropical Pacific Ocean mixed layer heat budget: The Pacific cold tongue. J. Phys. Oceanogr., 29, 69-81.

Tomas, R. A., J. R. Holton, and P. J. Webster, 1999: The influence of cross-equatorial pressure gradients on the location of nearequatorial convection. Quart. J. Roy. Meteor. Soc., 125, 11071127.

Wallace, J. M., T. P. Mitchell, and C. Deser, 1989: The influence of sea surface temperature on surface wind in the eastern equatorial Pacific: Seasonal and interannual variability. J. Climate, 2, 14921499.

Wang, W., and M. J. McPhaden, 1999: The surface-layer heat balance in the equatorial Pacific Ocean. Part I: The mean seasonal cycle. J. Phys. Oceanogr., 29, 1812-1831.

Weidman, P. D., D. L. Mickler, B. Dayyani, and G. H. Born, 1999: Analysis of Legeckis eddies in the near-equatorial Pacific. $J$. Geophys. Res., 104, 7865-7887.

Wentz, F. J., 1997: A well-calibrated ocean algorithm for special sensor microwave/imager. J. Geophys. Res., 102, 8703-8718.

, 1998: Algorithm theoretical basis document: AMSR Ocean Algorithm. Tech. Rep. 110398, Remote Sensing Systems, Santa Rosa, CA, 65 pp. [Available online at http://www.remss.com.] , and R. W. Spencer, 1998: SSM/I rain retrievals within a unified all-weather ocean algorithm. J. Atmos. Sci., 55, 1613-1627.

Xie, S.-P., M. Ishiwatari, H. Hashizume, and K. Takeuchi, 1998: Coupled ocean-atmospheric waves on the equatorial front. Geophys. Res. Lett., 25, 3863-3866.

Young, J. A., 1987: Boundary layer dynamics of tropical and monsoonal flows. Monsoon Meteorology, C.-P. Chang and T. N. Krishnamurti, Eds., Oxford University Press, 461-500.

Zhang, G. J., and M. J. McPhaden, 1995: The relationship between sea surface temperature and latent heat flux in the equatorial Pacific. J. Climate, 8, 589-605. 